\title{
Catalyzing Transitions to Sociality: Ecology Builds on Parental Care
}

\author{
Lluís Socias-Martínez ${ }^{1,2,3 *}$ and Peter M. Kappeler ${ }^{1,2,3}$ \\ ${ }^{1}$ Behavioral Ecology and Sociobiology Unit, German Primate Center, Leibniz Institute for Primate Research, Göttingen, \\ Germany, ${ }^{2}$ Department of Sociobiology/Anthropology, Johann-Friedrich-Blumenbach Institute of Zoology, Georg-August \\ University, Göttingen, Germany, ${ }^{3}$ Leibniz-Science Campus Primate Cognition, Göttingen, Germany
}

\section{OPEN ACCESS}

Edited by:

Patrizia d'Ettorre

Université Paris 13, France

Reviewed by:

Joël Meunier,

UMR7261 Institut de Recherche sur la Biologie de l'insecte (IRBI), France

Sheng-Feng Shen,

Biodiversity Research Center,

Academia Sinica, Taiwan

*Correspondence:

Lluís Socias-Martínez

Iluissociasm@gmail.com

Specialty section: This article was submitted to

Social Evolution,

a section of the journal

Frontiers in Ecology and Evolution

Received: 04 December 2018 Accepted: 23 April 2019

Published: 16 May 2019

Citation:

Socias-Martínez $L$ and Kappeler PM (2019) Catalyzing Transitions to

Sociality: Ecology Builds on Parental Care. Front. Ecol. Evol. 7:160. doi: 10.3389/fevo.2019.00160
In the context of social evolution research, great emphasis on kin-selected benefits has led to an understanding of parental care as one of the activities that helpers can perform in extended cooperative families. Nevertheless, this perspective might have precluded a deeper understanding of the implications of parental care for social evolution. We argue that parental care is a broader set of processes playing a key role both before and during the emergence of sociality. The care system of a species may be understood as the result of long coevolutionary processes with environmental pressures during presocial stages that impact transitions to sociality. We evaluate the present framework against evidence on the evolution of parental care and transitions toward sociality in subsocial and parasocial vertebrate and invertebrate species. Moreover, following previous evidence for the importance of modes of foraging and resting, we structure our inquiry by classifying societies into three types. Our results suggest that in "central place foragers" and "fortress defenders", ecological factors promoting the evolution of parental care foster a set of coevolutionary feedback loops resulting in increases in parental effort and offspring needs. Offspring needs alone or in combination with limited breeding options enhance the relative benefits of positive social interactions, catalyzing transitions to sociality. In "itinerant foragers", sociality is associated with colonizing new niches. Changes in predation pressure entail changes in the modes of care or selection for certain types of care already present in solitary ancestors. Further changes in the form of collective defense may be needed for permanent sociality to evolve. We conclude that there is evidence that social transitions to different types of societies are the result of long coevolutionary processes between environmental pressures and the care systems in a wide variety of taxa. Therefore, advances in the study of the origins of sociality may require further investigation of parental care evolution in solitary ancestors of today's social species.

Keywords: social evolution, social transition, sociality, ecology, parental care, dispersal, philopatry

\section{SOCIAL EVOLUTION}

The complexity of life has increased through successive transitions toward higher levels of organization (Maynard Smith and Szathmary, 1997; Okasha, 2006). Major steps in evolution have been explained by shifts from predominantly competitive toward more cooperative interactions between previously antagonistic entities in stressful ecological contexts (Kikvidze and Callaway, 2009). The evolution of group living (typically referred to as "sociality") is one example of these 
major steps in the evolution of life complexity that has occurred several times independently across vertebrates and invertebrates (Maynard Smith and Szathmary, 1997). Selfish individuals have come to align their fitness interests in cooperative interactions by some evolutionary process that provides the basis for living in groups.

We use the following definition of sociality: The permanent association between at least two adult individuals of the same sex that interact with each other more than with other individuals (Kappeler and van Schaik, 2002). This definition excludes pairs and associations between parents and immature offspring. This important distinction allows the targeting of efforts at understanding the origins of animal groups independently from the origins of family living. Although recent studies have attempted to integrate studies on the origins of sociality with those of family living (Costa, 2018; Kramer and Meunier, 2018), we prefer to keep sociality and family living conceptually separated in this review for several reasons. First, most current frameworks on social evolution consider variation in adult group size and sex composition (i.e., social organization) as the core for defining different social categories (Rubenstein and Abbot, 2017b). Thus, considering adults as core components of definitions of sociality is in accordance with previous definitions and studies. Second, the emphasis on adult sociality in previous definitions of sociality relates to a qualitative difference between species in which adults are solitary compared to those in which adults engage in regular social interactions with other adults, as for example reflected in studies linking social complexity with communicative complexity and cognition (Dunbar, 2009; Kappeler, 2019; Peckre et al., 2019). Third, equating family living with sociality may preclude the integration of mammals and birds in frameworks on the origins of sociality, since virtually all species have post-birth parental care and would accordingly be classified as social. Fourth, evolutionary transitions from solitary to social adults may occur in species where parents do not cohabitate with offspring (e.g., in parasocial mass-provisioning Hymenoptera). Thus, a definition of sociality based on adults is needed to include most vertebrate and invertebrate examples in a common framework. Finally, the evolutionary origins of pair living and family living have been extensively studied within the frameworks of sexual selection and parental care evolution, so that amalgamating parental care concepts with those of social evolution may result in misunderstandings hampering attempts to bridge both fields of inquiry.

Although group living is associated with numerous costs, the interactions that generate groups should yield positive fitness outcomes based on mutualism, cooperation or altruism. Such fitness benefits might not necessarily be synchronized; expected future fitness benefits of grouping might be sufficient to make individuals prone to associate (Kokko and Johnstone, 1999). Group formation thus relies on decisions that maximize either current or future fitness of individuals, or both.

Identifying determinants of sociality across species has proved difficult for several reasons (Elgar, 2015). First, research on social evolution has proceeded predominantly in a taxon-specific manner. As a result, frameworks developed for different taxa inevitably emphasized taxon-specific factors (Rubenstein and
Abbot, 2017b). Secondly, most previous studies focused on observed fitness costs and benefits of sociality in species that evolved sociality long ago. Deducing the origins of group living in these species may confound current functions and consequences of social behaviors with the actual causes of early forms of sociality. Addressing this issue is not trivial because several recent studies suggest that selective pressures at the origins of social life differed from those operating at derived stages, even in the same lineages (e.g., Sheehan et al., 2015; Griesser et al., 2017). Third, the most socially complex societies (i.e., cooperative breeding vertebrates and eusocial insects) are overrepresented in the literature and have thus been disproportionally influential in developing theories on social evolution. For instance, the kin selection and the ecological constraints models (Hamilton, 1964; Emlen, 1982) focus on conditions under which mature offspring would delay dispersal and help their parents or relatives to reproduce. Nonetheless, many other societies arise through mutualism between adult individuals of the same generation that might even be unrelated (Wcislo and Tierney, 2009). These latter types of explanations have received much less attention.

Recent calls for "social syntheses" that take into account the three limitations mentioned above (Elgar, 2015; Rubenstein and Abbot, 2017b) argue that studies on the causes of sociality should (i) rely on information from a wide variety of study organisms, (ii) give priority to information from species in which sociality is a recently evolved trait, and (iii) incorporate phylogenetically informed reconstructions of ancestral states and their subsequent derivate stages to generate a comprehensive framework of social evolution. Inspired by a recent volume summarizing work on social evolution in both vertebrates and invertebrates (Rubenstein and Abbot, 2017a), we suggest that revisiting the link between parental care, ecology, and social evolution might offer great potential for contributing to a social synthesis. Phylogenetically distant group-living species resemble each other in the way they develop and reproduce, as well as in the role they play in their ecosystem. Since these factors might impact the relative costs and benefits of grouping, we argue that there are pre-adaptations and environmental contexts that foster the evolution of sociality.

In this paper, we explore the idea that the appearance of sociality can result from a long history of coevolution between the caring system of a solitary species and its biotic and abiotic environment. The caring system has been suggested to represent one of four core elements of any social system that co-evolves with the three other components (social organization, social structure, and mating system) (Kappeler, 2019). We first present an overview of the ideas that linked parental care and social evolution in the past, then proceed to clarify our framework and close by reviewing the empirical evidence related to this notion.

\section{THE IMPORTANCE OF CARING SYSTEMS IN SOCIAL EVOLUTION}

\section{Subsocial Societies}

Several authors have argued that family units with extensive parental care might represent a common ancestral state that 
preceded the transition to cooperatively breeding societies in vertebrates and eusocial colonies in invertebrates (Wheeler, 1928; Emlen, 1995; Nalepa, 2010). Indeed, an association between post-birth forms of parental care and sociality relies on the fact that these groups are formed by the retention of adult offspring that delay or suppress dispersal and cooperate with their parents in parental care behaviors directed toward siblings. This process involving multiple generations has been described as the "subsocial route" toward eusociality in Hymenoptera (Michener, 1969, 1974) or the "extended family" in cooperatively breeding vertebrate societies (Emlen, 1995; Emlen et al., 1995). Even though the link between cooperative breeding/eusociality and parental care is at first glance self-evident, the causes for the appearance of these societies are still subject to controversy.

\section{Invertebrates}

An emphasis on indirect fitness benefits has characterized attempts to explain the evolution of sociality among invertebrates because individuals in these societies are in most cases highly related. Accordingly, societies were more likely to form where average inter-individual relatedness was high due to haplodiploidy, genetic monogamy, inbreeding or a combination thereof (Hamilton, 1964; Boomsma et al., 2011). However, another school of thought placed more importance on the caring system (Wheeler, 1928; Alexander, 1974; Emlen, 1995; Nalepa, 2010). Alexander (1974) already pointed out that parental manipulation, and not kin selection, was behind the origins of eusociality. He suggested that, because natural selection operates first in the parental generation, offspring altruism evolves when the parents' inclusive fitness is maximized independently of the effects on offspring's inclusive fitness. He emphasized that this process was dependent on the fact that parents, through parental care behaviors, could "manipulate" offspring development. Some recent empirical findings indeed support parental manipulation and not kin selection as an explanation for the evolution of eusociality (e.g., Kapheim et al., 2015). In addition, Nowak et al. (2010) suggested nest defense and extensive maternal care as the reasons for the evolution of eusociality. Thus, the caring system of eusocial lineages, and not only their average relatedness coefficients, may have to be considered in explanations of the origins of sociality.

Kramer and Meunier (2018) recently discussed the origins of invertebrate families with post-natal parental care and its relation to the evolution of sociality. They widened the taxonomic diversity considered by giving weight to examples of family interactions in precocial species. Moreover, they incorporated a "diachronic" explicit reasoning on social evolution by taking into account that caring systems evolved during the transition from precocial to altricial species and that "simple" precocial families might have preceded complex societies in which young are altricial (i.e., cooperative breeding and eusocial colonies). They suggested that to understand the origins of sociality, cooperative and competitive relationships among family members beyond parental care should be taken into account. Thus, the caring system needs to be considered in explaining the appearance of relatively simple societies as well.

\section{Vertebrates}

In vertebrates, the relationship between parental care and social evolution has been examined based on two main perspectives that emphasize the role of the environment. The first perspective posits that parental care sets the context for sociality to evolve because it creates the family unit. Once the family has evolved, depending on ecological conditions, offspring will or will not disperse ("Ecological constraints model") (Emlen, 1982). Such constraints have indeed been identified in several vertebrate (Komdeur, 1992; Walters et al., 1992; Hayes, 2000; Lucia et al., 2008) and invertebrate species (Brockmann, 1997). The second perspective views the family as a context in which parental care behaviors can be used by group members to increase their fitness ("Benefits of philopatry model") (Stacey and Ligon, 1991; Emlen, 1994). Indeed, many advantages, both in direct and indirect fitness, have been shown for philopatric individuals in the form of territory or breeding position inheritance, increased group size benefits on survival, and increased information or skills acquisition (Stacey and Ligon, 1991; Heg et al., 2011).

Nevertheless, the two perspectives are not mutually exclusive, and the example of the evolution of cooperative breeding in birds might well illustrate it. Avian cooperative breeding is associated with unpredictable and harsh environments, suggesting that philopatry evolved because of the indirect fitness benefits of cooperation under harsh conditions (Cornwallis et al., 2017). However, more informed phylogenetic reconstructions showed that philopatry without cooperation evolved previously in stable environments, preceding the appearance of cooperative breeding and the colonization of harsher biomes (Griesser et al., 2017). Thus, the study of the evolution of cooperative breeding in vertebrates suggests that the environment plays an essential role in social evolution. It does so by interacting with the caring system of the species and reinforces the idea that it is necessary to reconstruct the series of steps that sociality has followed.

Parental care in these examples is both the target of altruistic or cooperative interactions and the basis for evolving groups because these arise by adding adult offspring. However, if the numerous independent transitions toward sociality are analogous phenomena, our understanding of this process will come through comparing the origins of cooperative breeders with the origins of other types of societies.

Other "subsocial" societies-for example, communal breeders-neither show extensive alloparental care nor reproductive skew. This form of sociality is the most abundant among group-living vertebrates (Lewis and Pusey, 1997; Silk and Kappeler, 2017). The origins of these kinds of societies have also been explained as a result of an interaction between the caring system and ecological conditions. Emlen and Oring (1977) incorporated sex differences in parental investment to predict under which conditions polygynous vs. monogamous mating systems would evolve among mammals. In doing so, they also predicted under which conditions previously solitary females would become social. However, why females and not males? As females make higher parental 
investment and their fitness is therefore more dependent on the availability of resources, maternal investment would result in competition between females. Thus, only under certain conditions would females tolerate each other and become social.

Similarly, Wrangham (1980) predicted under which ecological conditions the transition toward group living would occur among primates. He hypothesized that female competition for resources arising from maternal care would give rise to a sort of prisoner's dilemma. A social phenotype would invade the population because groups, even though suffering from the costs of shared resources, would outcompete solitary individuals. Teaming up with related females against other females would produce the matrilineal societies characterizing most extant group-living primates. Therefore, even for communal breeders without cooperation in caring, social evolution may depend on the caring system of the ancestral solitary species.

One could test the importance of parental investment on social evolution by asking what the trajectory of social transitions would be in taxa where males are the sex investing more in care in the ancestral solitary species. Interestingly, in birdsa taxon characterized by pronounced paternal investment, and in which paternal care is supposed to be the common ancestral state (Wesolowski, 1994; Varricchio et al., 2008; but see Tullberg et al., 2002) - groups grow through an aggregation of males and not females. This pattern of group formation contrasts with most other societies and holds even in species where groups are composed of non-kin (Riehl, 2013). Thus, parental care might have played an essential role in the origin of sociality under various conditions.

\section{Parasocial Societies}

In some species, groups form through aggregation of individuals from the same generation after dispersal. This way of forming groups has been called the "parasocial route" toward eusociality in Hymenoptera (Michener, 1969, 1974). Because group formation occurs after dispersal, groups are formed in most cases by unrelated individuals. Interestingly, many of these parasocial non-kin societies cooperate in offspring care in diverse taxa (Clutton-Brock, 2002; Wcislo and Tierney, 2009; Riehl, 2013). For instance, in many species of bees and wasps, unrelated individuals join to cooperate in parental behaviors at a common nest (Wcislo and Tierney, 2009). In taxa with reproductive skew, parasocial societies may form as well (Brockmann, 1997). Such processes also occur in several vertebrate taxa, like fish and birds (Heg et al., 2011; Riehl, 2013). Thus, the relationship between sociality and parental care might relate to direct fitness benefits as well.

Taken together, theoretical frameworks and empirical evidence suggest that the interaction between caring systems and environmental conditions might be crucial for understanding the transition toward group living. Moreover, the role of parental care does not appear to be restricted to the origins of family-based societies and may apply as well to parasocial non-kin sociality.

\section{A FRAMEWORK INCORPORATING CARING SYSTEM EVOLUTION IN SOLITARY ANCESTORS}

Offspring are usually the most vulnerable stage of the life of an individual because perception and mobility are reduced compared to adults in most species. Predators and parasites might, therefore, be selected to preferentially target young individuals, creating complex interactions between a given species' range of parasites and predators and the evolution of parental care behaviors (Tallamy and Wood, 1986; Royle et al., 2016). These behaviors aim at increasing the survival and reproductive capacities of offspring. It is suggested that parental care is favored because of positive feedback loops that maximize the benefits of such behaviors for offspring. These loops are based on the evolving adaptation of the offspring phenotype that becomes increasingly dependent on the parents for correct development and survival (Royle et al., 2016; Kramer and Meunier, 2018).

In this article, we posit that parental care sets the preconditions for ecological factors to catalyze a transition toward sociality. We propose a series of evolutionary steps leading to sociality based on the coevolution between parental care and several environmental factors (Figure 1). The interaction between the environment and the caring system affects offspring survival and the available breeding opportunities, resulting in effects on the cost/benefit ratio of sociality.

An absence of parental care is the ancestral condition from which some form of parental care evolved (Royle et al., 2012). Firstly, (1, Figure 1) biotic or abiotic conditions that challenge offspring survival select for parental care (Brown et al., 2010; Klug and Bonsall, 2010; Pike et al., 2016; Royle et al., 2016). Parental care is by definition costly to the parents and should compensate for the adverse effects of the environment on offspring (Royle et al., 2012). Once parental care behaviors have evolved, two processes foster a further increase in parental expenditure. On the one hand, a self-reinforcing process on parental care arises from the fact that offspring adapt their mode of development to the care behaviors and become more dependent in a unidirectional trend (2, Figure 1) (Gardner and Smiseth, 2011; Royle et al., 2016; Kramer and Meunier, 2018). Simultaneously, coevolution with predators and parasites that challenge developing offspring sets up an arms race (3, Figure 1), generating more significant investment in parental care behaviors in turn (4, Figure 1) (Field and Brace, 2004; Royle et al., 2012; Yip and Rayor, 2014; Pike et al., 2016). Differences in the strength of processes 2 and 3 result in interspecific variation in the level of dependence on parental care for successful development and survival (i.e., precocial-altricial spectrum). For parents, increasing altriciality of offspring corresponds to increasing the minimum investment needed to raise offspring (4, Figure 1). Thus, any successful breeding attempt consumes more resources. Therefore, given this higher necessity, the carrying capacity of a given habitat becomes lower. In this sense, raising offspring successfully becomes increasingly complicated and the opportunities for breeding more limited (5, Figure 1). At this point, species under 


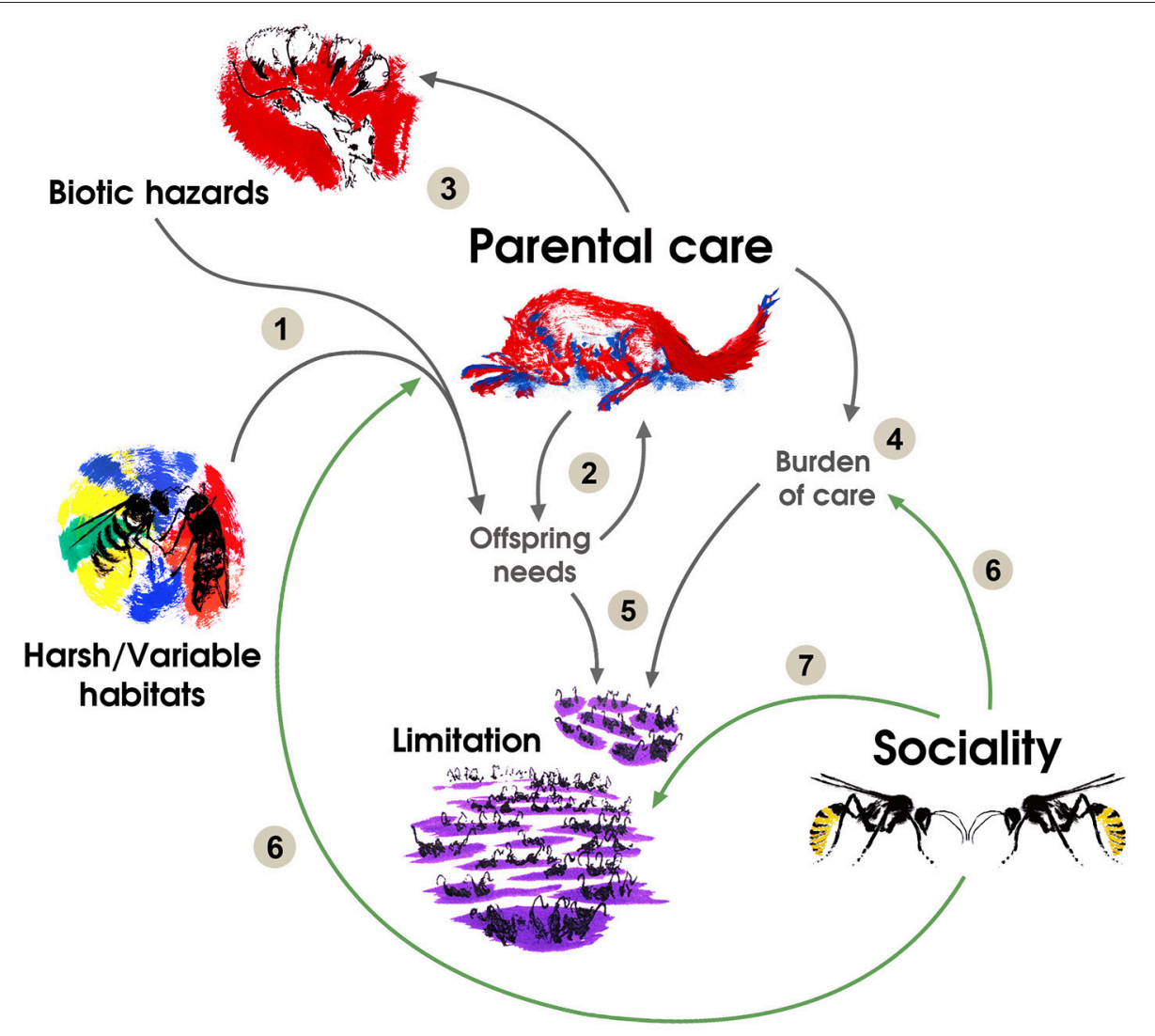

FIGURE 1 | The relationships between the evolution of parental care, environmental factors and social transitions can be summarized as follows: (1) Habitats or biotic hazards affecting offspring survival increase offspring needs. (2) This increase in offspring needs selects for parental care and generates a first positive feedback loop due to coevolution between offspring altriciality and care behaviors. (3) Predators and parasites coevolve with parental care in a second positive feedback loop selecting for more care. (4) Increases in care result in a higher burden per reproductive bout. (5) More sophisticated needs of offspring and a higher burden of care result in a lower carrying capacity and may result in limitation of breeding possibilities. (6) Sociality is heavily selected in species under processes (1, 2, 3, and 4) because it reduces the burden of care through mutualism or cooperative behaviors and reduces the impact of environmental pressures on offspring development and survival. (7) Sociality is selected in species under previous processes because it allows reducing limitation through sharing a reproductive resource, such as a suitable nesting place. In species with reproductive skew, social queuing for the breeding position is selected under limitated possibilities for solitary breeding resulting from processes (1, 2, 3, and 4). Drawings by LS-M.

ecological pressures that favor increased parental care (i.e., 2 and 3, Figure 1) possess parental care behaviors and a window for increasing fitness. The possibility of parental care behaviors and offspring benefits in solitary species with extensive parental care make the latter prone to benefit from social interactions (6, Figure 1). Byproduct mutualism or cooperation among previously competing individuals becomes adaptive in a context where a solitary breeder has low prospects of success because they buffer against processes 1, 3, or 4 (6 and 7, Figure 1). Positive interactions may come from other parents that possess a similar behavioral repertoire and are under the same burden of care (e.g., costs of constructing a nest), or from previous offspring whose fitness prospects of reproducing independently are too low.

Below, we review evidence for these processes from studies across vertebrates and invertebrates (see Supplementary Table 1). We proceed separately for societies that relate differently to their environment. We do so because how animals forage and rest could profoundly impact the evolutionary processes that we investigate (e.g., how parents can attempt to breed and avoid offspring mortality). Indeed, some authors have suggested the existence of broad types of societies based on how individuals interact with their milieu in terms of activity patterns and space usage for foraging and reproduction (Korb and Heinze, 2008). Two main types have been identified, named central place foragers (CPF) and fortress defenders (FD). Importantly, such idiosyncrasies in space use and activity patterns of societies were already present in their respective solitary ancestors. Thus, differentiating these categories is essential for testing the ecological scenarios in which sociality arose and the role played by parental care.

Central place foraging (CPF) characterizes a life structured around a specific place, usually a shelter, burrow or nest that serves as the home base for resting and rearing young. Spatial clustering of biologically relevant activities is a significant determinant of the ways through which sociality may enhance reproductive success in $\mathrm{CPF}$ species. $\mathrm{CPF}$ characterizes ants, bees, 
wasps, modern termites (i.e., separate-life-type), most communal and cooperative birds and mammals, kin-based societies in lizards and some cooperatively breeding cichlids (Rubenstein and Abbot, 2017b). Ants and separate-life-type termites will not be further discussed below because all extant species in the former are eusocial and the ancestral state of the latter was already social (Heinze et al., 2017; Korb and Thorne, 2017). Fortress defender (FD) societies live inside food resources, and the significant advantage of this way of life is to provide defense for developing offspring against predators or parasites. This lifestyle characterizes basal termites (i.e., one-piece of life type termites), polyembryonic wasps, gall-living aphids and thrips, snapping shrimps, ambrosia beetles and eusocial mole rats (Rubenstein and Abbot, 2017b). We suggest adding a third category, itinerant foragers (IF). Itinerant foraging species consist of groups of animals that move together during foraging and do not have a specific place for reproduction and resting. This pattern characterizes most diurnal group-living primates and ungulates, but also macropods and pelagic fish schools, among others.

Below, we review evidence for the proposed evolutionary processes in our framework in the proposed transitions to sociality in central place foragers first, followed by a comparison with fortress defenders and itinerant foragers. The structure of the text for each type of society analyzes first the evidence for processes leading to increases in parental care (1 and 2, Figure 1), followed by evidence on social buffering against processes 3, 4 and 5 , followed by the evidence that sociality buffers against such factors (6 and 7, Figure 1).

\section{PARENTAL CARE AND SOCIAL TRANSITIONS IN CENTRAL PLACE FORAGERS}

Central place foraging is related to the presence of a nest structure in which offspring reside during development. In this sense, many central place foraging taxa, such as wasps, bees, altricial birds and nesting mammals exhibit similar parental behaviors: nest construction, guarding and/or provisioning offspring (Royle et al., 2012). Finding, constructing and defending suitable nests are adaptive responses to protect offspring from their major sources of mortality (Royle et al., 2012; Ibáñez-Álamo et al., 2015). Therefore, central place foraging is a combination of behaviors that ultimately allow securing a microenvironment for offspring development. Nevertheless, species in invertebrates and vertebrates show great variation in the extent of investment in or the presence of different types of care (Royle et al., 2012, 2016). We argue that there is a link between the processes that promote variation in the extent of parental care and social transitions. Thus, we first examine the processes that intensify parental care and then connect these evolutionary trajectories to the evolution of sociality.

\section{Factors Increasing Parental Care Parental Care Self-Reinforcement}

Once parental care evolved, it created a microhabitat for offspring. These improved conditions create opportunities for offspring to reallocate energy invested in traits that are not immediately necessary anymore, such as muscles or vision, toward growing, making them more altricial (Royle et al., 2016). Examples can be found in birds and mammals where nesting selected for offspring born without the capacity for foraging or thermoregulating autonomously (Royle et al., 2012).

Offspring adaptation, in turn, affects the efficiency of parental care behaviors already in place and may trigger competition among offspring for those components of care that are not shareable (Gardner and Smiseth, 2011). Parents may then be forced to invest more in care to compensate for the competitive disadvantages of some offspring, generating a positive feedback loop between parental care and offspring altriciality (Royle et al., 2016; Kramer and Meunier, 2018). Thus, parental care implies a coevolutionary process between parent and offspring phenotypes that may generate trends toward more care. However, parents and offspring occur in an environment with multiple biotic and abiotic factors that may also affect the evolution of parental care.

\section{Challenges to Offspring Survival or Development}

Abiotic or biotic challenges may promote the appearance of parental care (Tallamy and Wood, 1986; Royle et al., 2016). However, these challenges may persist due to their unpredictable character, their severity or because offspring have become more altricial. For instance, the transition toward provisioning through body reserves in the reptile taxa that gave rise to mammals is related to the unpredictability of the resources upon which they depended (Royle et al., 2012).

Moreover, the biotic hazards that parents try to reduce may evolve in response, creating a Red Queen effect between parental care and predation strategies, for example (Liow et al., 2011). These processes might be more important than previously thought. For instance, Bois and Mullin (2017) argue that nonavian dinosaur extinction relates to the appearance of new types of nest predators during the late Cretaceous. Nevertheless, explicit theories and tests for an arms race between parental care and biotic hazards for offspring have not yet been incorporated into models of parental care evolution.

A key example of the impact of biotic hazards on the enhancement of parental investment comes from Hymenoptera. Two main ways of offspring food provisioning exist in this taxon. The most primitive and common form is "mass provisioning," where females collect the food offspring will need to develop before laying the egg(s) and then put them together into a constructed nest (Field, 2005). In the derived form of "progressive provisioning," mothers continuously bring food to the developing larvae, which is costly in terms of productivity (Field, 2005). The transition from mass to progressive provisioning has been related to the risks of predation and parasitism. Following the evolution of nesting with mass provisioning, some parasites adapted by finding their way to larvae either concealed inside the prey items provided or during the brief moments where parents introduce the egg with the prey into the nest cell. Progressive provisioning decreases this risk because mothers malaxate prey before delivering it to their offspring, thereby destroying potential parasites that would otherwise attack larvae (Field and Brace, 2004; Hunt and Toth, 2017). Moreover, contrary to 
mass provisioning species, offspring encounter kleptoparasites more often after the egg stage, and larvae resist parasites better than eggs (Field and Brace, 2004). Thus, although both types of provisioning include nesting and certain protection, coevolution with predators fostered the evolution of more complex modes of provisioning in Hymenoptera. Importantly, the mode of provisioning has been related to the evolution of eusociality (see section Assuring Care: Shared Provisioning). Therefore, given the plausible importance of coevolutionary processes with other species on parental care, we argue that research focusing specifically on this link might offer great potential for understanding social evolution.

Overall, abiotic and biotic hazards as well as interactions among family members appear to drive increases in parental care. In an evolutionary process selecting for innovations against everincreasing pressures on offspring survival, sociality may appear as a new solution to an old problem because it may buffer the costs of care and/or increase the efficiency of care. Next, we review examples of proposed selective forces for the transition toward sociality that build on these two types of benefits arising from associations between individuals.

\section{Sociality Buffers Against Harsh or Variable Environments}

Harsh or variable environments have been suggested as contexts in which grouping might offer benefits to both parents and offspring. Several types of abiotic properties or agents, their spatial and temporal variability as well as the distribution of food resources play a role in this context.

\section{Increasing the Efficiency of Care: Sharing a Nest}

Homoeothermic vertebrates are energetically challenged by temperatures exceeding a certain range. Most of these species have altricial young that need to be assisted in thermoregulation and provisioned with food by their parents to survive. The time parents spend foraging creates a trade-off with offspring thermoregulation, as offspring left at non-optimal temperatures may die or develop less efficiently. Groups of several adults may reduce the impact of this tradeoff for reproducing individuals via social thermoregulation. For instance, in bats, matrilines are prevalent in species that inhabit cold environments and are thought to have arisen because grouping helps lactating females by increasing thermoregulation efficiency of pups and mothers (Kerth, 2008). Similarly, some group-living rodents and primates inhabiting thermally challenging environments are thought to benefit from grouping through improved thermoregulation (Madison, 1984; Perret, 1998). Such environments offer an incentive for parents to join their nests, which increases the efficiency of thermoregulation (i.e., reached optimal temperature lasts longer) or metabolism (i.e., conversion of food into body mass). Thus, for species with altricial young, harsh abiotic conditions may generate opportunities for increasing fitness by cooperating with other parents.

Environmental variability may constitute a different dimension of ecological harshness. Variability of the environment may concern abiotic factors like temperature, $\mathrm{pH}$ or humidity, or the spatial or temporal heterogeneity of food or shelters. A recent game-theoretical model suggested that environmental variability can enhance the benefits of altruism between relatives, making altruism an evolutionarily stable strategy (Kennedy et al., 2018). This effect arises because in a variable environment cooperation results in bet-hedging. Cooperation reduces variability in reproductive success between generations exposed to different environments, offering an advantage to lineages with altruists. These lineages might be at a disadvantage when conditions are benign but make a greater difference when conditions become harsher by maintaining a similar level of reproductive success overall (Kennedy et al., 2018). During harsh times, the mean reproductive success of a population is low, and a subtle difference in the number of offspring produced makes a big difference in terms of relative contribution to the next generation. Non-cooperators are at the mercy of environmental variability, while lineages with altruists buffer such changes. A recent evaluation of the environmental correlates of sociality in Polistes wasps indicated that variability in ambient temperature, rendering the conditions for larvae development and adult foraging less suitable, has favored a parasocial transition toward nest sharing (Sheehan et al., 2015). The evolutionary mechanism underlying these patterns may involve bet-hedging in foraging success under challenging environments.

Indeed, an older model proposed a similar bet-hedging effect arising from group foraging. Groups might be at an advantage because grouping reduces variability in foraging success (Wenzel and Pickering, 1991). In this model, it is assumed that foraging bouts by a group lead to more constant foraging success (e.g., Baker et al., 1981; Caraco, 1981; Stevens et al., 2007). Interestingly, a similar explanation was proposed for the appearance of eusocial groups in mole rats. In the few rodent species exhibiting this social system, foraging is very costly and at high risk of bearing no reward due to the patchiness of the tubercles they depend on (Lovegrove and Wissel, 1988). Group foraging is thought to reduce the risk of a zero-reward bout happening and therefore reduces overall variability in foraging success. Hence, cooperation would help group members to overcome environmental variability at the expenses of the current payoffs. Although this notion has been phrased in a kin selection perspective, mutualism, reciprocal altruism or social queuing could also offer a context for such benefits of sociality against environmental variability. Therefore, the generality of this mechanism could be greater than previously thought.

Overall, caring activities performed in groups or by more than one individual separately may reduce the detrimental effects of environmental variability by flattening differences in outcomes of parental activities. This effect translates into benefits because variability of conditions might result in non-optimal development of offspring (e.g., Marczak and Richardson, 2008; Kingsolver et al., 2009). If cooperative behaviors can buffer against harshness or variability in environmental conditions, sociality can be seen as the vehicle to generate stability. If sociality buffers against variability, it should translate into more constant reproductive success between generations (Kennedy et al., 2018). Long-term data on reproductive success in different generations of facultative social species would be required to test this prediction. 


\section{Sociality Buffers Against Biotic Hazards}

Nesting in CPF has major implications for social evolution because, firstly, in many species nesting implies costs of finding and constructing a nest that can be shared. Secondly, due to the concealment of offspring in safe places, parents face a tradeoff between foraging and guarding/incubating in the solitary ancestors of social CPF species. The severity of such a tradeoff can be alleviated by the presence of other parents.

\section{Increasing the Efficiency of Care: Shared Nest Guarding}

In $\mathrm{CPF}$ species, guarding the nest to deter predators and protect offspring is traded off against foraging. Adults may increase guarding time as by-product mutualism just by increasing proximity to other nests (Wcislo and Fewell, 2017). The time offspring are guarded increases with any temporal mismatch in visits by parents even in the absence of turn-taking. Shared nest guarding might thus be one of the earliest benefits of sociality in species facing these constraints and may not require any specific trait besides an increase in tolerance among parents (Wcislo and Fewell, 2017).

Despite its theoretical importance, only a few studies have investigated the effect of shared nest guarding on reduced predation or parasitism in bees and wasps, and they found mixed results (Abrams and Eickwort, 1981; McCorquodale, 1989; Wcislo et al., 1993; Soucy and Giray, 2003; Prager, 2014; Ohkubo et al., 2018). Among mammals, female rodents benefit from communal nesting with respect to guarding time. They are able to spend more time away from the nest when engaging in communal nesting while letting pups alone for a similar amount of time than solitary nesting females (Auclair et al., 2014). Because outside activities relate to the amount of resources females will obtain, mothers might benefit directly from communal nesting, and pups should benefit from enhanced maternal condition. Additionally, female black-and-white ruffed lemurs that nested near other females experienced higher reproductive success due to arising antipredator benefits of proximity (Baden, 2019). These few vertebrate examples illustrate our point that sharing a nest may offer parents the possibility to alleviate the tradeoff between guarding and foraging that solitary central place foraging species face.

\section{Intraspecific Threats: Shared Nest Guarding}

The presence of intraspecific exploitative strategies may develop and act as an additional motor for the evolution of grouping. Infanticide risk is thought to be one such evolutionary force, but nesting communally can increase pup survival by reducing infanticide risk (Manning et al., 1995; Hayes, 2000). In fact, in the only group-living felid, lionesses defend their cubs better against infanticidal males when living in groups (Lewis and Pusey, 1997). In the few social species of lizards in the genus Egernia, infanticide is thought to have favored the retention of offspring in extended families because the presence of the parents decreases aggression toward young (Lanham and Bull, 2000; Post, 2000; O'Connor and Shine, 2004).

Additionally, marauding conspecifics may try to usurp costly breeding resources, such as already built nests, especially when time runs out for seasonal breeders. For instance, parasocial associations of reproductive females in Polistes wasps with reproductive skew, have been used as models for the study of early benefits of nest sharing (Hunt and Toth, 2017). In these species, nests that have a near-to-emergence worker generation are of great value because emerging workers will raise the offspring of any reproductive, even an eventual usurper. Sharing a nest is thought to help prevent this type of intraspecific parasitism in several species, as cooperating females are better able to deter marauding conspecifics [reviewed in Brockmann (1997)].

Interestingly, in the handful of bird species where females lay eggs in the same nest and care for them communally, this reproductive strategy has evolved in species whose ancestors suffered from intraspecific brood parasitism, or where both strategies coexist in the same population (Zink, 2000; Riehl, 2013). One of the processes that could make associations adaptive would be that females laying communally are better able to defend their nests against brood parasites. No test of this hypothesis has been carried out to our knowledge. Interspecific brood parasitism has also been suggested to have acted as a driving force in the evolution of cooperative breeding in birds, but it is not clear whether it is a force promoting the appearance of groups or a force enhancing cooperation once the transition has already occurred (Feeney et al., 2013).

Thus, CPF species that nest with dependent offspring in response to selective pressures from the environment still face inter- and intraspecific offspring mortality arising from the tradeoff between nest guarding and foraging. Nest sharing appears to provide a widespread and convergent solution to ameliorate this tradeoff.

\section{Assuring Care: Shared Provisioning}

In some species, parental care has evolved toward provisioning offspring when parents are more efficient than offspring at finding food or when food provisioned by parents is of higher quality (Gardner and Smiseth, 2011). Parental feeding of young is extremely costly to the residual reproductive value of parents (Royle et al., 2012), and it may lead to a point of no return when offspring become completely dependent on parents for survival (Kramer and Meunier, 2018). At this point, offspring and parental survival become coupled, which can have implications for social evolution (Gadagkar, 1990).

A strong link between the evolution of eusociality and the presence of extensive parental care in the form of progressive provisioning has been established for Hymenoptera (Michener, 1985; Schwarz et al., 2003; Field and Brace, 2004; Field, 2005). Although nesting with progressive provisioning provides benefits against several types of offspring predators (see previous section Challenges to Offspring Survival or Development), two important costs are associated with this type of parental care. Contrary to mass provisioning, in species with progressive provisioning, offspring survival is dependent on the presence of the mother during the entire developmental period (Field, 2005).

Sharing the nest with other females can reduce this cost. Nest sharing allows increased guarding time (see section Increasing the Efficiency of Care: Shared Nest Guarding), and, if provided by an alloparent, it decouples parental and offspring mortality. 
If a provisioning adult dies, other parents in the nest can continue caring for the young, providing dependent offspring in progressive provisioning species with central place foraging with a survival possibility (West-Eberhard, 1975; Gadagkar, 1990). The evolution of eusociality in Hymenoptera has been related more strongly to this "life insurance" strategy than to kin selection by some authors (West-Eberhard, 1975; Gadagkar, 1990). A similar explanation has been offered for the evolution of communal nesting in a facultatively social primate species, the gray mouse lemur (Eberle and Kappeler, 2006) and in several species of mice (Boyce and Boyce, 1988). Thus, "life insurance" can act as a driver of sociality in taxonomically distant CPF species. Importantly, this benefit might drive sociality in species with and without reproductive skew, as the above examples show. Thus, parental care and its evolution in relation to hazards from the environment impose constraints that can be ameliorated by grouping, and this might be a common ground for the evolution of different types of sociality.

\section{Limited Breeding Possibilities Lead to Sociality}

Researchers studying altricial birds have long pointed out that the appearance of cooperative breeding may be linked to a limitation in the availability of breeding sites (Emlen, 1982). Accordingly, to this habitat saturation hypothesis, in stable habitats species reach their carrying capacity where resources for breeding are in shortage. Unpredictable variation in environmental conditions may also lead to mismatches between previous productivity and current capacity of the habitat. Furthermore, habitat variability has been linked to the regular production of more offspring than can be supported by the environment (Royle et al., 2012). This is thought to be a form of bet-hedging mediated through the production of offspring that vary phenotypically as an outcome of enhanced competition for parental resources. Thus, the caring system of a species, together with its evolutionary history and the environment, may influence the availability of breeding positions.

Similar to the effects of limitation of food resources or the territories that sustain them, shortage in nesting site availability might promote sociality. The primitive way of nesting in bees depends on the excavation of ground nests (Wcislo and Fewell, 2017). In many habitats, soil characteristics constrain the possibility of excavating to suitable patches, which is thought to have led same-generation individuals to share a nest, cooperating in nest excavation and guarding. Likewise, in reptiles the aggregation of unrelated individuals has been linked to a limitation of refuges (Graves and Duvall, 1995), and the few squamate reptiles that live in extended family groups all depend on patchily distributed refuges, such as tree hollows and rock outcrops (Chapple, 2003; Michael et al., 2010; Davis et al., 2011; Rabosky et al., 2012). In mammals, group formation by related females in rodents and bats is supposed to be facilitated by a limitation of suitable burrows or roosts required for reproduction (e.g., Moses and Millar, 1992; Wolff, 1994; Chaverri et al., 2007; Kerth, 2008). In birds, it has been proposed that habitat saturation, and therefore a limitation of breeding sites, has selected for delayed dispersal and helping (Emlen, 1982; Komdeur, 1992). This hypothesis has been supported by a phylogenetic analysis showing that delayed dispersal and family-living in stable habitats preceded the appearance of cooperative breeding (Griesser et al., 2017). There is therefore strong evidence that the limitation of the space or the resources necessary for breeding favors sharing in central place foragers.

\section{Limited Breeding Opportunities Lead to Social Queuing in Societies With Reproductive Skew}

Reproductive skew is a complex phenomenon, involving decisions by dominants and subordinates on group composition and reproduction. Societies with reproductive skew may arise directly from solitary ancestors and not through intermediate steps where reproduction is progressively monopolized (Rubenstein et al., 2016). Their transition to sociality also builds on the limitations arising from the needs of extensive parental care. In Stenogastrine wasps, for example, social queuing for a breeding position under limitation of nesting sites offers a more plausible explanation for the evolution of sociality than kin selection since relatedness between females is below 0.5 (Strassmann et al., 1994). In other wasp families, such as Polistes and sphecid wasps, the high costs of independent reproduction discussed above have been proposed as the main drivers of kin-based groups (Brockmann, 1997). Nevertheless, although suitable breeding sites might not be limiting in Polistes, the fact that independent breeding is extremely costly makes social queuing also a suitable strategy for them (Queller et al., 2000). Therefore, the limitation of reproductive opportunities may have contributed importantly to the evolution of reproductive skew societies.

Similar evidence for the role of nest limitation in facilitating transitions to sociality has been reported for vertebrates. For instance, parasocial groups of coral reef goby fish are made up by a reproductive couple that monopolizes reproduction and unrelated individuals that join them in a common coral. Joining individuals queue to attain a breeding position under a situation of habitat saturation (Wong et al., 2007), and limitation of coral shelter has been experimentally supported as a mechanism for group formation (Holbrook et al., 2000; Wong, 2010; Wong et al., 2012). Similarly, cooperative breeding in birds has been explained by means of social queuing (e.g., Reyer, 1986; Piper et al., 1995; Sloane, 1996). Contrary to Hymenoptera, however, cooperative societies in birds are mainly based on male helping (Riehl, 2013). This difference might be due to a combination of social queuing and sexual selection pressures arising from biparental care. As an initial benefit, birds in groups are suggested to experience lower predation risk, which allows the evolution of strategies that maximize future fitness (Koenig and Mumme, 1987). Parental care plays an important role here because male helpers are chosen as future breeding partners based on their previous parental performance (e.g., Griggio et al., 2004), and this type of female choice has been proposed as a general mechanism for the evolution of paternal care (Alonzo, 2012). 


\section{Overview of Social Transitions in Central Place Foragers}

In summary, the evidence reviewed above suggests that parental care might be a common catalyst for the independent evolution of societies with and without reproductive skew in CPF species. When young depend on parental care due to the coevolution with biotic hazards or to abiotic conditions that threaten offspring survival, two effects on sociality ensue. First, the costs of parental care can be shared with other parents. Second, the costs of parental care coupled with offspring altriciality restrains reproductive possibilities, which, in turn, enhances the relative benefits of shared parental activities. In species with reproductive skew, these benefits, compared to solitary breeding, are so important as to sacrifice current fitness by queuing for the breeding position.

\section{PARENTAL CARE AND SOCIAL TRANSITIONS IN FORTRESS DEFENDERS}

Fortress defender societies consist of eusocial or cooperative families living inside a structure that serves both as protection against biotic and abiotic hazards and as their main feeding resource. Next, we review evidence for an interaction between environmental hazards and the caring system of ancestral species and their relation to social transitions in fortress defenders across different taxa. We consider web spiders as fortress defenders because their activities occur in the web and they do not need to leave offspring unattended to forage.

\section{Factors Increasing Parental Care}

Different forms of nesting in fortress defenders are thought to serve a protective function against biotic and abiotic challenges. These nesting strategies were already present before the transitions toward sociality. For example, the evolution of gall-inducing behaviors in thrips and aphids, or different nesting strategies in other species, such as gluing together phyllodes (leaf-like plant structures) to build up nests, may be understood as a form of parental care (Crespi et al., 1997). Because gallforming has evolved multiple times, but has never been lost, such unidirectionality may indicate the presence of similar selfreinforcement or coevolutionary processes as in central place foragers. In support of this notion, gall-forming species of thrips have an array of specialized gall predators and parasitoids that coevolved with them. Similarly, maternal care in spiders is common and has been shown to protect against egg desiccation, and against parasites and predators (Yip and Rayor, 2014).

\section{Sociality Buffers Against Harsh Environments}

The evolution of sociality might also be mediated through a certain scarcity or difficulty of exploiting food resources that impact offspring development. For instance, in both aphids and thrips, eusociality has been linked to slow development of larvae in non-optimal host plants (Stern, 1998; Crespi et al., 2004). It has also been suggested that slow development selects for the evolution of soldiers that protect offspring during a prolonged period of vulnerability. Similarly, the evolution of termite eusociality from a family-living ancestor with biparental care has been explained by means of a dietary-induced slow developmental mode (Nalepa, 1994). In Cryptotermes species, sister taxa of termites used as a model for their ancestral condition, development into adult morphs requires several years, an unusually long developmental period for an insect. In addition, in order to digest wood, termites and their ancestors depend on endosymbiotic cellulose-degrading bacteria. These bacteria need to be socially transmitted after each molt, making family living obligatory (Thorne, 1997). This suggests that altriciality and parental care coevolved long before the transition toward eusociality occurred in the termites. The enlargement of the time window for offspring development has negative consequences because parasites and predators have more opportunities to prey on them (see next section Sociality Buffers Against Biotic Hazards). Taken together, evidence from aphids, thrips and termites suggests that the scarcity or low quality of the main food resources resulted in prolonged offspring development, creating a window for primitive forms of sociality (parent-offspring and sibling-sibling associations) to become lifelong.

Communal breeding groups of thrips occur within closely related lineages of those containing eusocial species. Groups are founded by unrelated females, and nests are not gall structures but constructed by gluing plant parts together. These groups share the costs of nest construction and enjoy benefits for offspring against aridity of the environment (Gilbert, 2014; Abbot and Chapman, 2017).

Spider transitions toward cooperative sociality have occurred in lineages where there is construction of a web and where maternal care takes place beyond the first instar (Yip and Rayor, 2014; Avilés and Guevara, 2017; Viera and Agnarsson, 2017). Harsh habitats, i.e., where strong rains are common, are associated with extended families exhibiting cooperative breeding (Avilés et al., 2007). In these species, webs are expensive to construct and periodical destructions by intense rains represent an important constraint on solitary living (Purcell and Avilés, 2008). Forming groups with relatives is supposed to be advantageous because periodical nest-reconstruction costs are shared (Avilés and Guevara, 2017). Thus, species in which maternal care went beyond the egg phase were able to colonize harsh habitats through retention of mature offspring.

Thus, sociality in fortress defenders appears to buffer them against direct impacts of abiotic conditions on offspring survival. Moreover, benefits from cooperating in nest construction in these conditions foster social transitions through both the subsocial and parasocial route.

\section{Sociality Buffers Against Biotic Hazards}

Fortress defenders do not have to leave their offspring unattended because they nest on their feeding source. Nevertheless, coevolution with predators and parasites might have driven their transitions to sociality to some extent as well. For instance, despite having evolved a concealed mode of life inside gall structures, thrips and aphids suffer from attacks by specialist predators and parasitoids (Crespi et al., 1997; Abbot and 
Chapman, 2017). The evolution of thrip eusociality from a family-living ancestor has therefore been linked to the presence of specific gall invading species (Crespi et al., 2004). In the ancestral species, mothers found a gall after mating and care for their developing offspring through producing antimicrobial secretions and displaying defensive behaviors against predators until dispersal. In eusocial species, soldiers are the first brood to be born in the gall and help to protect the future offspring (Crespi et al., 2004; Kutsukake et al., 2009; Turnbull et al., 2012). The evolution of soldiers (which entails sociality between adults) is selected by predation pressure and may be seen as a means of protecting offspring. Furthermore, soldier behavioral repertoires derive from maternal behaviors in brood defense behaviors against parasites and predators in solitary ancestors (Crespi et al., 2004). Moreover, in some species, parasocial societies made up by unrelated adult females may perform coordinated nest guarding and defense with repellent chemicals against potential predators (Crespi et al., 1997). Thus, the first forms of adult sociality both through the subsocial and parasocial routes relate to cooperation against biotic threats.

In spiders, sociality through the subsocial route has been linked to habitats where predation pressure is especially salient due to a high diversity of predator species (Yip and Rayor, 2014; Viera and Agnarsson, 2017). Moreover, cooperative breeding in the genus Anelosimus has been linked to high probability of maternal death analogously to the "life insurers" in CPF (Viera and Agnarsson, 2017) (see section Assuring Care: Shared Provisioning). Sociality through the retention of mature offspring has evolved in lineages that already disposed of antipredator adaptations to biotic hazards through maternal care. Sociality is therefore a further response toward predation risk, allowing successful colonization of certain habitats.

Biotic hazards may also relate to the evolution of fortress defenders in the marine environment, but here they impact adult survival. Snapping shrimp and coral reef gobies living inside sponges and corals, respectively, suffer from high predation risk outside their shelter (Herler et al., 2011; Hultgren et al., 2017). This risk is thought to have forced unrelated individuals to share refuges through the parasocial route (Herler et al., 2011; Hultgren et al., 2017). In shrimps, this risk has resulted in pairs sharing a common sponge, with each pair reproducing independently, and in species where eusociality has evolved through retention of larvae (Chak et al., 2017). In gobies, some species form groups with one breeding pair monopolizing reproduction and no cooperation in egg care by subordinates (Wong, 2010). Therefore, although predation risk selected for a concealed mode of life in the solitary ancestors of these marine fortress defenders, this is not a result of offspring vulnerability and parental care. In these species, biotic hazards that foster a concealed mode of life for adults resulted in transitions to sociality through a limitation of shelter.

Thus, predation and parasitism relate to sociality in very different types of fortress defenders. Maternal or biparental care initially evolved in response to biotic hazards, and their reinforcement further selected for cooperation with conspecifics for the defense of dependent offspring. Such benefits of sociality on processes derived from parental care evolution appear to be common for subsocial and parasocial transitions in FD species belonging to different taxa. An exception may be found in marine societies of FD, because predation risk driving sociality in these habitats acted more strongly on adults.

\section{Limited Breeding Possibilities Lead to Sociality}

In social aphids and thrips, limitation of suitable sites to form galls has been suggested to favor parasocial associations between adult females that cofound galls (Kiester and Strates, 1984; Abbot and Chapman, 2017). In snapping shrimp, the sponges where these animals live are in short supply (Macdonald et al., 2006), making it difficult for juveniles to find unoccupied hosts. This limitation is thought to favor the sharing of nests between multiple reproducing pairs in communal species that form through the parasocial route.

The appearance of eusocial snapping shrimp has occurred through the evolution of a non-dispersing larval stage. In noneusocial species, larvae develop in the water column and then settle in a new sponge after dispersal (Duffy and Macdonald, 2010). This evolutionary transition might have occurred for two reasons in relation to habitat saturation. On the one hand, larvae may be using this strategy to increase their inclusive fitness by helping their parents to reproduce instead of trying to colonize a new sponge and face their current occupants. On the other hand, by staying and cooperating, young shrimps improve the ability of their colony to monopolize a sponge in the face of habitat saturation. This benefit of philopatry is indirectly confirmed by the fact that eusocial species are ecologically dominant (Macdonald et al., 2006; Chak et al., 2017).

Thus, animals with very different life histories might have evolved sociality in response to situations of shortage of shelters or food resources. This transition mainly occurred either because passive sharing of a common resource might indeed be the best response to a general situation of shortage. Alternatively, sharing might be the basis for the development of a cooperative group that defends resources against other conspecifics in a situation of general competition.

\section{Overview on Social Transitions in Fortress Defenders and Comparison With Central Place Foragers}

The evolution of a concealed mode of life in fortress defenders is a response to environmental hazards analogous to the evolution of nesting in CPF. Certain fortress defender ancestors made a transition toward sociality by the specialization of first broods into soldier morphs that defend developing siblings. These soldiers protect developing offspring against specialized predators, and their defensive capacity is an exaptation of parental defensive behaviors in their solitary ancestors. In this case, the coevolution between predators and parental behaviors made cooperation with offspring or with other parents (in the case of parasocial transitions) advantageous. This process matches the described evolution of joint nesting in central place foragers. Limitation of suitable places for breeding is also a derived feature from the previous processes that is common for 
both subsocial and parasocial transitions in fortress defenders and in central place foragers. Although some authors have proposed that $\mathrm{CPF}$ and $\mathrm{FD}$ are different types of societies because offspring in the former can feed independently, offspring vulnerability might be an analogous problem in both groups. Thus, we conclude that there is evidence for a common role of parental care and its relation to the environmental conditions at the origins of these two types of societies.

\section{PARENTAL CARE AND SOCIAL TRANSITIONS IN ITINERANT FORAGERS}

Itinerant foraging societies are characterized by a nomadic lifestyle. Permanent movement of adults hampers concealed nesting of dependent offspring and offers a striking contrast to central place foragers and fortress defenders. In itinerant foragers, social evolution coincides with shifts in the mode of offspring care and transitions toward new niches characterized by high predation risk. The order of these changes remains unknown, but our review below will help to identify predictions for future comparative tests.

\section{Factors Increasing Parental Care}

The same biotic and abiotic hazards that affect the ancestors of central place foragers and fortress defenders may have shaped the forms of parental care found among itinerant foragers. In both ungulates and primates, caching offspring is the ancestral form of maternal care; in more derived species, offspring accompany adults during foraging (Kappeler, 1998; Fisher et al., 2002). Comparative analyses suggested that in ungulate species that colonized open habitats, young were selected to develop a following strategy due to increased visibility and the associated predation risk (Fisher et al., 2002). Although following young are classified as precocial, these ungulates have longer developmental times, and comparisons between sympatric hider and follower species suggested higher maternal investment in the latter (Carl and Robbins, 1988). Thus, following may represent a derived antipredatory strategy associated with higher maternal investment as a response to predation risks for offspring in open habitats.

In primates, the colonization of the diurnal niche is associated with the loss of nesting and the adoption of infant transport on the maternal body (Kappeler, 1998). Infant carrying is associated with reduced infanticide risk (van Schaik and Kappeler, 1997), and it may also reduce infants' predation risk. Other benefits of infant carrying, like unrestricted maternal foraging, must be traded off against attendant costs, especially the energetic costs of carrying, which are particularly high for smaller species where the offspring/mother weight ratio is higher (Ross, 2001). Species with infant carrying have smaller home ranges, which has been interpreted as evidence for increased maternal energetic burden (Ross, 2001). Thus, it appears that for both primates and ungulates, the evolution of a new mode of parental care with increased maternal investment is associated with the colonization of a new niche entailing higher predation risk.

\section{Sociality Buffers Against Biotic Hazards}

In IF, social evolution coincides with transitions toward new niches characterized by high predation risk. Groups of itinerant foragers are more conspicuous but are also able to detect predators earlier and, in some species, mount a collective defense (Berger, 1979; Dehn, 1990). Moreover, the individual risk of being predated upon decreases in groups (Hamilton, 1971). Thus, sociality has been interpreted primarily as an antipredator strategy. Independently, the evolution of offspring transport has also been associated with the transition toward the new niches that promoted sociality (Fisher et al., 2002). Thus, it is possible that this social transition was influenced by the modes of care of solitary ancestors in primates and ungulates.

Evidence suggests that offspring hiding strategies preclude group membership during infant dependence (e.g., Costelloe and Rubenstein, 2015). An offspring following strategy, on the contrary, might have facilitated the evolution of permanent sociality in IF species. The Alaskan moose may serve as a model species to understand social transitions in ungulates from this perspective (Molvar and Bowyer, 1994). This species appears to have only recently become social, and calves use a following strategy (Popp et al., 2018). There is variability in the social organization ranging from solitary to small foraging groups usually composed of several related females occasionally joined by males (Miquelle et al., 1992; Colson et al., 2016). Traditional theory states that foraging efficiency increases with sociality because per capita vigilance should decrease. Nevertheless, in this primitively social ungulate, foraging efficiency decreased with group size due to within-group aggression and increased per capita time of vigilance. At the same time, groups were able to forage further from forest cover where they have access to additional food resources (Molvar and Bowyer, 1994). Interestingly, females adopted a solitary strategy when having dependent offspring. Therefore, infant following might not be sufficient to trigger permanent sociality, and other factors may be needed.

Since no grooming and no cooperative defense were ever observed during the Alaskan moose study, the authors suggested that in the absence of cooperative behaviors to deter predators, grouping could result in higher mortality of offspring because predators would preferentially target them due to their reduced mobility. Supporting this idea, several studies have indeed found predator preferences for offspring (Mech and Boitani, 2003; Hayward et al., 2006; Barber-Meyer and Mech, 2008). Moreover, early joining of the herd by calves has been associated with group defense in African bovids (Estes, 1974). Findings in the Alaskan moose might be a model for understanding the transition in other ungulate species, because the clade shares a general intolerance toward conspecifics (Molvar and Bowyer, 1994) that could preclude cooperation in the early stages of sociality. Thus, it is possible that cooperation in parental care behaviors at the group level is necessary for ungulates to overcome higher mortality risks for offspring when living in groups.

In primates, the transition to group living is thought to be associated with the colonization of the diurnal niche by a nocturnal ancestor. The diurnal niche offered an advantage of aggregating with other individuals against predation while 
foraging through visual detection (Alexander, 1974; van Schaik, 1983). Phylogenetic reconstructions appear to support this hypothesis with a transition from an ancestral solitary forager to a species with loose aggregations of unrelated individuals of both sexes (Shultz et al., 2011). However, group living in diurnal primates is also associated with infant carrying (Kappeler, 1998; Nakamichi and Yamada, 2009). Thus, it is possible that from the variation shown in the modes of care in nocturnal primates, species that readily took advantage of the diurnal niche were those that already transported their offspring. Nevertheless, reconstructions of social transitions in primates did not take into account the complexity of social systems among nocturnal strepsirrhines, which include species where female groups cooperatively raise offspring (Radespiel et al., 2001; Schülke and Kappeler, 2003; Eberle and Kappeler, 2006). This fact may suggest that sociality evolved before a transition into the diurnal niche and that it was based on female cooperation for raising offspring.

Predation risk likely determined the evolution of group living in these evolutionary transitions in ungulates and primates. However, if the transitions occurred while colonizing open areas or a diurnal niche, respectively, permanent group living evolved only when caring of infants was possible while foraging in group. Although female ungulates regularly attack predators to protect offspring, only group cooperation may have allowed permanent group living. In primates, sociality also benefited adults with respect to antipredator behavior, but the transition occurred together with a change in infant carrying. This coevolutionary pattern suggests that the ecological pressures driving sociality built on the caring system of the solitary ancestors of both primates and ungulates.

\section{Limited Breeding Possibilities Lead to Sociality}

Group living ungulates inhabit mostly open habitats and feed mainly on herbaceous vegetation. Dependence on such lowquality food and the fact that following strategies are costly suggest a certain limitation for females that has resulted in slower life histories (Fisher et al., 2002). However, limitation for resources may have played little role in the social evolution of ungulates since the food they depend on is nearly ubiquitous and their offspring care strategies are independent of specific resources, such as nesting sites.

In primates, competition for limited food resources, such as fruiting trees, may have promoted transition to communal breeding. Wrangham (1980) hypothesized that female competition for resources would give rise to cooperative female associations out-competing solitary individuals for access to clumped resources. The fact that most group living primates retain female offspring could support this hypothesis (Clutton-Brock and Lukas, 2012), but the relative role of limitation of feeding resources compared with the role of predation is still unresolved (Janson, 2000; Thierry, 2008). Moreover, inbreeding avoidance might also determine female philopatry (Lukas and Clutton-Brock, 2011). Cooperative breeding in primates has evolved only once in callitrichids from a pair-living ancestor (Lukas and Clutton-Brock, 2012). This transition is thought to relate to a general limitation of suitable territories that result in social queuing mostly by unrelated males (Yamamoto, 2006). Moreover, these species have among the highest offspring/mother weight ratio, resulting in costs of care that benefit from male helpers. Since groups are at an advantage at raising offspring (Bales et al., 2000), groups may be considered as a breeding resource for breeders analogously to colonies in primitively eusocial Hymenoptera or groups in cooperatively breeding birds.

\section{Overview of Social Transitions in Itinerant Foragers and Comparison With Central Place Foragers and Fortress Defenders}

A transition to itinerant foraging sociality appears to be linked predominantly to predation on adults. However, reconstruction of the ancestral caring systems and the ecological contexts where sociality appeared reveals that the modes of infant care shaped this process. Firstly, it is possible that species that already had infant transport or following were those that transitioned toward sociality, or at least this transition was made more often by these species. Secondly, in ungulates further cooperative behaviors between adults in defense against predation events may be necessary for the evolution of permanent sociality. Thirdly, in the few primate species with cooperative breeding, the high costs of care of infant transport in small-bodied species promoted cooperation with other individuals.

Infant transport is a derived trait in IF species that evolved prior to the emergence of sociality. Sociality was favored in concert with changes of the previous niche and attendant changes in predation risk. Thus, in CPF and FD species, coevolution with predators may have led to nesting, altriciality and limitation in breeding possibilities that together made sociality advantageous, while in IF species ecological changes permitted or necessitated a change of the infant caring mode that may have precipitated the change toward group living. Thus, there are differences in the nature of the processes leading to sociality in the three different types of societies. In IF species, the change in predation risk was the result of a niche change, while in CPF and FD species, this change occurred passively through coevolution with predators and parasites.

\section{DISCUSSION AND CONCLUSIONS}

The origins and complexity of social systems in different taxa have been explained by a bewildering diversity of factors (Rubenstein and Abbot, 2017a). This diversity has hampered identifying general patterns of social evolution across the animal kingdom (Elgar, 2015). In this review, we have established a link between parental care and the ecological contexts promoting evolutionary transitions in social systems. In very different taxa, abiotic and biotic challenges to offspring survival and dynamics between parents and offspring lead to more complex parental care behaviors over time, and these behaviors become increasingly expensive (1, 2, 3, and 4, Figure 1). This increasing burden of care, together with vulnerability of offspring 
and further environmental challenges, leads to a limitation in breeding possibilities that sets the stage for cooperative or mutualistic strategies to invade the population $(5,6$, and 7, Figure 1).

By linking social evolution and parental care we have 1) shown that factors promoting the appearance of parental care (i.e., environmental hazards) also relate to its maintenance and further modification through coevolutionary feedbacks with predators and parasites. This idea contrasts with mainstream theory on parental care evolution, where the link between origins and subsequent modification is not made explicit or is even denied (e.g., Royle et al., 2012, 2016). It is possible that a predominant emphasis on interactions within the "family" (i.e., sexual conflict over care, parent-offspring conflict and sibling rivalry) has precluded including ecological interactions with other species that could play an important role in parental care evolution. We have presented evidence from different taxa indicating that parasites, predators and changing conditions do not only foster the appearance of caring behaviors, but may also deeply enhance their expression and further change.

Moreover, our framework posits 2) that parental care is a main piece in the evolutionary puzzle leading to sociality. This notion appears to be in contrast with suggestions that other interactions than parent-offspring care may be more important to understand the changes in caring systems that led to sociality (Kramer and Meunier, 2018), for two reasons. First, the two frameworks differ in how much emphasis is paid on interactions within the family. Kramer and Meunier (2018) emphasize knowledge on the subsocial route toward sociality and consider parasociality only for aggregations of larvae, whereas we try to explain the subsocial and parasocial routes toward adult sociality by emphasizing that cooperation between adults may be a widespread phenomenon independent of kinship.

Second, different conclusions also arise from different definitions of parental care. Kramer and Meunier (2018) consider only immediate parent-offspring interactions as parental care, whereas we consider any parental behavior, also if it is displayed by another adult individual. Furthermore, Kramer and Meunier (2018) consider that family systems evolve from precocial to altricial, and that the evolution of sociality might be affected by within-family interactions during these changes. Although we agree with this conclusion, we point out that quite a few solitary species have single offspring (mammals) and the shift from precocial to altricial is not made in a context where cooperation or competition between siblings or parents can take place (Hymenoptera). Moreover, we also take into account that parental care components prior to hatching or birth may affect

\section{REFERENCES}

Abbot, P., and Chapman, T. (2017). "Sociality in aphids and thrips," in Comparative Social Evolution, eds D. R. Rubenstein and P. Abbot (Cambridge, UK: Cambridge University Press), 154-187.

Abrams, J., and Eickwort, G. C. (1981). Nest switching and guarding by the communal sweat bee Agapostemon virescens (Hymenoptera, Halictidae). Insectes Sociaux 28, 105-116. doi: 10.1007/BF02223699 social evolution as well. The construction of a nest, which is induced by coevolution with predators and parasites or harsh environments, appears as a major feature catalyzing subsocial and parasocial transitions across vertebrates and invertebrates. Thus, instead of being alternative, the two frameworks might nourish each other in a complementary way when differences in perspective and definitions are made evident.

Reviewing evidence for the present framework we have shown 3) that the origins of sociality may be triggered by similar processes in societies with different kin structure and degrees of reproductive skew. In particular, our survey revealed a key role for the caring systems of a species in promoting sociality. However, explicit tests of this hypothesis will need phylogenetically informed reconstructions of changes in parental care, environmental hazards and social systems.

Research on social evolution has to date paid much attention to the evolution of sociality through reproductive altruism and the derived cooperative activities and conflicts that arise in such societies. In this paper, we have tried to emphasize that understanding the transition from a solitary to a social lifestyle is intrinsically connected to an understanding of the patterns of parental care in the ancestral solitary species. We encourage researchers in social and parental care evolution to further investigate the possible links between these two key evolutionary processes with comparative methods in a wide range of taxa.

\section{AUTHOR CONTRIBUTIONS}

LS-M: original idea and drawings. LS-M and PK: writing of the manuscript.

\section{ACKNOWLEDGMENTS}

LS-M is very grateful to Louise Peckre for precious encouragement and discussions during the writing and revision of the first drafts of the manuscript and to Antoni Socias Albaladejo for digital processing of figures. LS-M and PK thank the reviewers, Joël Meunier and Sheng-Feng Shen, for helping improving the quality of the manuscript with their valuable critics and insights. This research was funded by the Deutsches Primatenzentrum $\mathrm{GmbH}$.

\section{SUPPLEMENTARY MATERIAL}

The Supplementary Material for this article can be found online at: https://www.frontiersin.org/articles/10.3389/fevo. 2019.00160/full\#supplementary-material 
benefits associated with communal nesting. Anim. Behav. 92, 143-149. doi: 10.1016/j.anbehav.2014.03.008

Avilés, L., Agnarsson, I., Salazar, P. A., Purcell, J., Iturralde, G., Yip, E. C., et al. (2007). Altitudinal patterns of spider sociality and the biology of a new midelevation social Anelosimus species in Ecuador. Am. Nat. 170, 783-792. doi: $10.1086 / 521965$

Avilés, L., and Guevara, J. (2017). "Sociality in spiders," in Comparative Social Evolution, eds D. R. Rubenstein and P. Abbot (Cambridge, UK: Cambridge University Press), 188-223.

Baden, A. L. (2019). A description of nesting behaviors, including factors impacting nest site selection, in black-and-white ruffed lemurs (Varecia variegata). Ecol. Evol. 9, 1010-1028. doi: 10.1002/ece3.4735

Baker, M. C., Belcher, C. S., Deutsch, L. C., Sherman, G. L., and Thompson, D. B. (1981). Foraging success in junco flocks and the effects of social hierarchy. Anim. Behav. 29, 137-142. doi: 10.1016/S0003-3472(81)80160-1

Bales, K., Dietz, J., Baker, A., Miller, K., and Tardif, S. D. (2000). Effects of allocaregivers on fitness of infants and parents in callitrichid primates. Folia Primatol. (Basel) 71, 27-38. doi: 10.1159/000021728

Barber-Meyer, S., and Mech, L. (2008). Factors influencing predation on juvenile ungulates and natural selection implications. USGS North. Prairie Wildl. Res. Cent. 4, 8-29. doi: 10.2461/wbp.2008.4.2

Berger, J. (1979). "Predator harassment" as a defensive strategy in ungulates. Am. Midl. Nat. 102, 197-199. doi: 10.2307/2425087

Bois, J., and Mullin, S. J. (2017). Dinosaur nest ecology and predation during the Late Cretaceous: was there a relationship between upper Cretaceous extinction and nesting behavior? Hist. Biol. 29, 976-986. doi: 10.1080/08912963.2016.1277423

Boomsma, J. J., Beekman, M., Cornwallis, C. K., Griffin, A. S., Holman, L., Hughes, W. O., et al. (2011). Only full-sibling families evolved eusociality. Nature 471, E4-E5; author reply E9-10. doi: 10.1038/nature09832

Boyce, C. C., and Boyce, J. L. (1988). Population biology of Microtus arvalis. I. Lifetime reproductive success of solitary and grouped breeding females. J. Anim. Ecol. 57, 711-722. doi: 10.2307/5088

Brockmann, H. J. (1997). Cooperative breeding in wasps and vertebrates: the role of ecological constraints. Evol. Soc. Behav. Insects Arachn. 347, 348-371. doi: 10.1017/CBO9780511721953.018

Brown, J. L., Morales, V., and Summers, K. (2010). A key ecological trait drove the evolution of biparental care and monogamy in an amphibian. Am. Nat. 175, 436-446. doi: 10.1086/650727

Caraco, T. (1981). Risk-sensitivity and foraging groups. Ecology 62, 527-531. doi: $10.2307 / 1937716$

Carl, G. R., and Robbins, C. T. (1988). The energetic cost of predator avoidance in neonatal ungulates: hiding versus following. Can. J. Zool. 66, 239-246. doi: 10.1139/z88-034

Chak, S. T. C., Duffy, J. E., Hultgren, K. M., and Rubenstein, D. R. (2017). Evolutionary transitions towards eusociality in snapping shrimps. Nat. Ecol. Evol. 1:0096. doi: 10.1038/s41559-017-0096

Chapple, D. G. (2003). Ecology, life-history, and behavior in the Australian scincid genus Egernia, with comments on the evolution of complex sociality in lizards. Herpetol. Monogr. 17, 145-180. doi: 10.1655/07331347(2003)017[0145:ELABIT]2.0.CO;2

Chaverri, G., Quirós, O. E., Gamba-Rios, M., and Kunz, T. H. (2007). Ecological correlates of roost fidelity in the tent-making bat Artibeus watsoni. Ethology 113, 598-605. doi: 10.1111/j.1439-0310.2007.01365.x

Clutton-Brock, T. (2002). Breeding together: kin selection and mutualism in cooperative vertebrates. Science 296, 69-72. doi: 10.1126/science.296.5565.69

Clutton-Brock, T. H., and Lukas, D. (2012). The evolution of social philopatry and dispersal in female mammals. Mol. Ecol. 21, 472-492. doi: 10.1111/j.1365-294X.2011.05232.x

Colson, K. E., White, K. S., and Hundertmark, K. J. (2016). Parturition site selection in moose (Alces alces): evidence for social structure. J. Mammal. 97, 788-797. doi: 10.1093/jmammal/gyw006

Cornwallis, C. K., Botero, C. A., Rubenstein, D. R., Downing, P. A., West, S. A., and Griffin, A. S. (2017). Cooperation facilitates the colonization of harsh environments. Nat. Ecol. Evol. 1:0057. doi: 10.1038/s41559-016-0057

Costa, J. T. (2018). The other insect societies: overview and new directions. Curr. Opin. Insect Sci. 28, 40-49. doi: 10.1016/j.cois.2018.04.008
Costelloe, B. R., and Rubenstein, D. I. (2015). Coping with transition: offspring risk and maternal behavioural changes at the end of the hiding phase. Anim. Behav. 109, 217-225. doi: 10.1016/j.anbehav.2015.08.022

Crespi, B. J., Carmean, D. A., and Chapman, T. W. (1997). Ecology and evolution of galling thrips and their allies. Annu. Rev. Entomol. 42, 51-71. doi: 10.1146/annurev.ento.42.1.51

Crespi, B. J., Morris, D. C., and Mound, L. A. (2004). Evolution of Ecological and Behavioural Diversity: Australian Acacia Thrips as Model Organisms. Canberra, ACT: Australian Biological Resources Study.

Davis, A. R., Corl, A., Surget-Groba, Y., and Sinervo, B. (2011). Convergent evolution of kin-based sociality in a lizard. Proc. R. Soc. Lond. B Biol. Sci. 278, 1507-1514. doi: 10.1098/rspb.2010.1703

Dehn, M. M. (1990). Vigilance for predators: detection and dilution effects. Behav. Ecol. Sociobiol. 26, 337-342. doi: 10.1007/BF00171099

Duffy, J. E., and Macdonald, K. S. (2010). Kin structure, ecology and the evolution of social organization in shrimp: a comparative analysis. Proc. R. Soc. Lond. B Biol. Sci. 277, 575-584. doi: 10.1098/rspb.2009.1483

Dunbar, R. I. (2009). The social brain hypothesis and its implications for social evolution. Ann. Hum. Biol. 36, 562-572. doi: 10.1080/03014460902960289

Eberle, M., and Kappeler, P. M. (2006). Family insurance: kin selection and cooperative breeding in a solitary primate (Microcebus murinus). Behav. Ecol. Sociobiol. 60, 582-588. doi: 10.1007/s00265-006-0203-3

Elgar, M. A. (2015). Integrating insights across diverse taxa: challenges for understanding social evolution. Front. Ecol. Evol. 3:124. doi: $10.3389 /$ fevo.2015.00124

Emlen, S. T. (1982). The evolution of helping. I. An ecological constraints model. Am. Nat. 119, 29-39. doi: 10.1086/283888

Emlen, S. T. (1994). Benefits, constrainsts and the evolution of the family. Trends Ecol. Evol. 9, 282-285. doi: 10.1016/0169-5347(94)90030-2

Emlen, S. T. (1995). An evolutionary theory of the family. Proc. Natl. Acad. Sci. U.S.A. 92, 8092-8099. doi: 10.1073/pnas.92.18.8092

Emlen, S. T., and Oring, L. W. (1977). Ecology, sexual selection, and the evolution of mating systems. Science 197, 215-223. doi: 10.1126/science.327542

Emlen, S. T., Wrege, P. H., and Demong, N. J. (1995). Making decisions in the family: an evolutionary perspective. Am. Sci. 83, 148-157.

Estes, R. D. (1974). Social organization of the African Bovidae. Behav. Ungulates Relat. Manag. 1, 166-205.

Feeney, W. E., Medina, I., Somveille, M., Heinsohn, R., Hall, M. L., Mulder, R. A., et al. (2013). Brood parasitism and the evolution of cooperative breeding in birds. Science 342, 1506-1508. doi: 10.1126/science.1240039

Field, J. (2005). The evolution of progressive provisioning. Behav. Ecol. 16, 770-778. doi: 10.1093/beheco/ari054

Field, J., and Brace, S. (2004). Pre-social benefits of extended parental care. Nature 428, 650-2. doi: 10.1038/nature02427

Fisher, D. O., Blomberg, S. P., and Owens, I. P. (2002). Convergent maternal care strategies in ungulates and macropods. Evolution 56, 167-176. doi: 10.1111/j.0014-3820.2002.tb00858.x

Gadagkar, R. (1990). Evolution of eusociality: the advantage of assured fitness returns. Phil. Trans. R. Soc. Lond. B 329, 17-25. doi: 10.1098/rstb.1990.0146

Gardner, A., and Smiseth, P. T. (2011). Evolution of parental care driven by mutual reinforcement of parental food provisioning and sibling competition. Proc. $R$. Soc. B Biol. Sci. 278, 196-203. doi: 10.1098/rspb.2010.1171

Gilbert, J. D. (2014). Thrips domiciles protect larvae from desiccation in an arid environment. Behav. Ecol. 25, 1338-1346. doi: 10.1093/beheco/aru128

Graves, B. M., and Duvall, D. (1995). Aggregation of squamate reptiles associated with gestation, oviposition, and parturition. Herpetol. Monogr. 9, 102-119. doi: $10.2307 / 1466999$

Griesser, M., Drobniak, S. M., Nakagawa, S., and Botero, C. A. (2017). Family living sets the stage for cooperative breeding and ecological resilience in birds. PLoS Biol. 15:e2000483. doi: 10.1371/journal.pbio.2000483

Griggio, M., Matessi, G., and Pilastro, A. (2004). Should I stay or should I go? Female brood desertion and male counterstrategy in rock sparrows. Behav. Ecol. 16, 435-441. doi: 10.1093/beheco/ari009

Hamilton, W. D. (1964). The genetical evolution of social behaviour. II. J. Theor. Biol. 7, 17-52. doi: 10.1016/0022-5193(64)90039-6

Hamilton, W. D. (1971). Geometry for the selfish herd. J. Theor. Biol. 31, 295-311. doi: 10.1016/0022-5193(71)90189-5 
Hayes, L. D. (2000). To nest communally or not to nest communally: a review of rodent communal nesting and nursing. Anim. Behav. 59, 677-688. doi: 10.1006/anbe.1999.1390

Hayward, M. W., O’Brien, J., Hofmeyr, M., and Kerley, G. I. H. (2006). Prey preferences of the African wild dog Lycaon pictus (Canidae: Carnivora): ecological requirements for conservation. J. Mammal. 87, 1122-1131. doi: 10.1644/05-MAMM-A-304R2.1

Heg, D., Rothenberger, S., and Schürch, R. (2011). Habitat saturation, benefits of philopatry, relatedness, and the extent of co-operative breeding in a cichlid. Behav. Ecol. 22, 82-92. doi: 10.1093/beheco/arq170

Heinze, J., Kellner, K., and Seal, J. (2017). “Sociality in ants," in Comparative Social Evolution, eds D. R. Rubenstein and P. Abbot (Cambridge, UK: Cambridge University Press), 21-49.

Herler, J., Munday, P. L., and Hernaman, V. (2011). "Gobies on coral reefs," in The Biology of Gobies, eds R. A. Patzner, J. L. Van Tassell, M. Kovacic, and B. G. Kapoor (Jersey, NJ: CRC Press), 493-529.

Holbrook, S. J., Forrester, G. E., and Schmitt, R. J. (2000). Spatial patterns in abundance of a damselfish reflect availability of suitable habitat. Oecologia 122, 109-120. doi: 10.1007/PL00008826

Hultgren, K., Duffy, J. E., and Rubenstein, D. R. (2017). “Sociality in shrimps," in Comparative Social Evolution, eds D. R. Rubenstein and P. Abbot (Cambridge, UK: Cambridge University Press), 224-250.

Hunt, J. H., and Toth, A. L. (2017). "Sociality in wasps," in Comparative Social Evolution, eds D. R. Rubenstein and P. Abbot (Cambridge, UK: Cambridge University Press), 84-123.

Ibáñez-Álamo, J. D., Magrath, R. D., Oteyza, J. C., Chalfoun, A. D., Haff, T. M., Schmidt, K. A., et al. (2015). Nest predation research: recent findings and future perspectives. J. Ornithol. 156, 247-262. doi: 10.1007/s10336-015-1207-4

Janson, C. H. (2000). Primate socio-ecology: the end of a golden age. Evol. Anthropol. Issues News Rev. Issues News Rev. 9, 73-86. doi: 10.1002/(SICI)1520-6505(2000)9:2<73::AID-EVAN2>3.0.CO;2-X

Kapheim, K. M., Nonacs, P., Smith, A. R., Wayne, R. K., and Wcislo, W. T. (2015). Kinship, parental manipulation and evolutionary origins of eusociality. Proc. $R$. Soc. B Biol. Sci. 282:20142886. doi: 10.1098/rspb.2014.2886

Kappeler, P. M. (1998). Nests, tree holes, and the evolution of primate life histories. Am. J. Primatol. 46, 7-33. doi: 10.1002/(SICI)1098-2345(1998)46:1<7::AID-AJP3>3.3.CO;2-D

Kappeler, P. M. (2019). A framework for studying social complexity. Behav. Ecol. Sociobiol. 73:13. doi: 10.1007/s00265-018-2601-8

Kappeler, P. M., and van Schaik, C. P. (2002). Evolution of primate social systems. Int. J. Primatol. 23, 707-740. doi: 10.1023/A:1015520830318

Kennedy, P., Higginson, A. D., Radford, A. N., and Sumner, S. (2018). Altruism in a volatile world. Nature 555:359. doi: 10.1038/nature25965

Kerth, G. (2008). Causes and consequences of sociality in bats. AIBS Bull. 58, 737-746. doi: 10.1641/B580810

Kiester, A. R., and Strates, E. (1984). Social behaviour in a thrips from Panama. J. Nat. Hist. 18, 303-314. doi: 10.1080/00222938400770231

Kikvidze, Z., and Callaway, R. M. (2009). Ecological facilitation may drive major evolutionary transitions. Bioscience 59, 399-404. doi: 10.1525/bio.2009.59.5.7

Kingsolver, J. G., Ragland, G. J., and Diamond, S. E. (2009). Evolution in a constant environment: thermal fluctuations and thermal sensitivity of laboratory and field populations of Manduca sexta. Evolution 63, 537-541. doi: 10.1111/j.1558-5646.2008.00568.x

Klug, H., and Bonsall, M. B. (2010). Life history and the evolution of parental care. Evol. Int. J. Org. Evol. 64, 823-835. doi: 10.1111/j.1558-5646.2009.00854.x

Koenig, W. D., and Mumme, R. L. (1987). Population Ecology of the Cooperatively Breeding Acorn Woodpecker. Princeton University Press.

Kokko, H., and Johnstone, R. A. (1999). Social queuing in animal societies: a dynamic model of reproductive skew. Proc. R. Soc. Lond. B Biol. Sci. 266, 571-578. doi: 10.1098/rspb.1999.0674

Komdeur, J. (1992). Importance of habitat saturation and territory quality for evolution of cooperative breeding in the Seychelles warbler. Nature 358, 493. doi: $10.1038 / 358493 \mathrm{a} 0$

Korb, J., and Heinze, J. (2008). “The ecology of social life: a synthesis," in Ecology of Social Evolution, eds J. Korb and J. Heinze (Berlin; Heidelberg: Springer), 245-259.

Korb, J., and Thorne, B. (2017). "Sociality in termites," in Comparative Social Evolution, eds D. R. Rubenstein and P. Abbot (Cambridge, UK: Cambridge University Press), 124-153.
Kramer, J., and Meunier, J. (2018). The other facets of family life and their role in the evolution of animal sociality. Biol. Rev. 94, 199-215. doi: 10.1111/brv.12443

Kutsukake, M., Shibao, H., Uematsu, K., and Fukatsu, T. (2009). Scab formation and wound healing of plant tissue by soldier aphid. Proc. R. Soc. Lond. B Biol. Sci. 276, 1555-1563. doi: 10.1098/rspb.2008.1628

Lanham, E. J., and Bull, C. M. (2000). Maternal care and infanticide in the Australian skink, Egernia stokesii. Herpetol. Rev. 31:151.

Lewis, S. E., and Pusey, A. E. (1997). "Factors influencing the occurrence of communal care in plural breeding mammals," in Communal Breeding in Mammals, eds N. G. Solomon and J. A. French (Cambridge, UK: Cambridge University Press), 335-363.

Liow, L. H., Van Valen, L., and Stenseth, N. Chr. (2011). Red Queen: from populations to taxa and communities. Trends Ecol. Evol. 26, 349-358. doi: 10.1016/j.tree.2011.03.016

Lovegrove, B. G., and Wissel, C. (1988). Sociality in molerats: metabolic scaling and the role of risk sensitivity. Oecologia 74, 600-606. doi: 10.1007/BF00 380059

Lucia, K. E., Keane, B., Hayes, L. D., Lin, Y. K., Schaefer, R. L., and Solomon, N. G. (2008). Philopatry in prairie voles: an evaluation of the habitat saturation hypothesis. Behav. Ecol. 19, 774-783. doi: 10.1093/beheco/ $\operatorname{arn} 028$

Lukas, D., and Clutton-Brock, T. (2012). Cooperative breeding and monogamy in mammalian societies. Proc. R. Soc. Lond. B Biol. Sci. 279, 2151-2156. doi: $10.1098 / \mathrm{rspb} .2011 .2468$

Lukas, D., and Clutton-Brock, T. H. (2011). Group structure, kinship, inbreeding risk and habitual female dispersal in plural-breeding mammals. J. Evol. Biol. 24, 2624-2630. doi: 10.1111/j.1420-9101.2011.02385.x

Macdonald, K. S., Ríos, R., and Duffy, J. E. (2006). Biodiversity, host specificity, and dominance by eusocial species among sponge-dwelling alpheid shrimp on the Belize Barrier Reef. Divers. Distrib. 12, 165-178. doi: 10.1111/j.1366-9516.2005.00213.x

Madison, D. M. (1984). "Group nesting and its ecological and evolutionary significance in overwintering microtus rodents," in Winter Ecology of Small Mammals, ed J. F. Merritt (Pittsburg, CA: Carnegie Museum of Natural History), 267-274.

Manning, C. J., Dewsbury, D. A., Wakeland, E. K., and Potts, W. K. (1995). Communal nesting and communal nursing in house mice, Mus musculus domesticus. Anim. Behav. 50, 741-751. doi: 10.1016/0003-3472(95) 80134-0

Marczak, L. B., and Richardson, J. S. (2008). Growth and development rates in a riparian spider are altered by asynchrony between the timing and amount of a resource subsidy. Oecologia 156, 249-258. doi: 10.1007/s00442-008-0989-y

Maynard Smith, J., and Szathmary, E. (1997). The Major Transitions in Evolution. Oxford, UK: Oxford University Press.

McCorquodale, D. B. (1989). Nest defense in single-and multifemale nests of Cerceris antipodes (Hymenoptera: Sphecidae). J. Insect Behav. 2, 267-276. doi: 10.1007/BF01053298

Mech, L. D., and Boitani, L. (2003). Wolf: Behavior, Ecology, and Conservation. Chicago, IL: University of Chicago Press.

Michael, D. R., Cunningham, R. B., and Lindenmayer, D. B. (2010). The social elite: habitat heterogeneity, complexity and quality in granite inselbergs influence patterns of aggregation in Egernia striolata (Lygosominae: Scincidae). Austral. Ecol. 35, 862-870. doi: 10.1111/j.1442-9993.2009. 02092.x

Michener, C. D. (1969). Comparative social behavior of bees. Annu. Rev. Entomol. 14, 299-342. doi: 10.1146/annurev.en.14.010169.001503

Michener, C. D. (1974). The Social Behavior of the Bees: A Comparative Study. Cambridge, MA: Harvard University Press.

Michener, C. D. (1985). "From solitary to eusocial: need there be a series of intervening species?," in Experimental Behavioural Ecology and Sociobiology, ed L. Holldobler (Fortschr Zool), 293-305.

Miquelle, D. G., Peek, J. M., and Van Ballenberghe, V. (1992). Sexual segregation in Alaskan moose. Wildl. Monogr. 122, 3-57.

Molvar, E. M., and Bowyer, R. T. (1994). Costs and benefits of group living in a recently social ungulate: the Alaskan moose. J. Mammal. 75, 621-630. doi: $10.2307 / 1382509$

Moses, R. A., and Millar, J. S. (1992). Behavioural asymmetries and cohesive mother-offspring sociality in bushy-tailed wood rats. Can. J. Zool. 70, 597-604. doi: $10.1139 / \mathrm{z} 92-088$ 
Nakamichi, M., and Yamada, K. (2009). Distribution of dorsal carriage among simians. Primates 50:153. doi: 10.1007/s10329-009-0134-5

Nalepa, C. A. (1994). "Nourishment and the origin of termite eusociality," in Nourishment and Evolution in Insect Societies Westview Studies in Insect Biology, eds J. H. Hunt and C. A. Nalepa (Boulder, CO: Westview Press), 57-104.

Nalepa, C. A. (2010). Altricial development in subsocial cockroach ancestors: foundation for the evolution of phenotypic plasticity in termites. Evol. Dev. 12, 95-105. doi: 10.1111/j.1525-142X.2009.00394.x

Nowak, M. A., Tarnita, C. E., and Wilson, E. O. (2010). The evolution of eusociality. Nature 466:1057. doi: 10.1038/nature09205

O'Connor, D. E., and Shine, R. (2004). Parental care protects against infanticide in the lizard Egernia saxatilis (Scincidae). Anim. Behav. 68, 1361-1369. doi: 10.1016/j.anbehav.2004.02.014

Ohkubo, Y., Yamamoto, T., Ogusu, N., Watanabe, S., Murakami, Y., Yagi, N., et al. (2018). The benefits of grouping as a main driver of social evolution in a halictine bee. Sci. Adv. 4:e1700741. doi: 10.1126/sciadv. 1700741

Okasha, S. (2006). The levels of selection debate: philosophical issues. Philos. Compass 1, 74-85. doi: 10.1111/j.1747-9991.2006.00001.x

Peckre, L., Kappeler, P. M., and Fichtel, C. (2019). Clarifying and expanding the social complexity hypothesis for communicative complexity. Behav. Ecol. Sociobiol. 73:11. doi: 10.1007/s00265-018-2605-4

Perret, M. (1998). Energetic advantage of nest-sharing in a solitary primate, the lesser mouse lemur (Microcebus murinus). J. Mammal. 79, 1093-1102. doi: $10.2307 / 1383001$

Pike, D. A., Clark, R. W., Manica, A., Tseng, H.-Y., Hsu, J.-Y., and Huang, W.-S. (2016). Surf and turf: predation by egg-eating snakes has led to the evolution of parental care in a terrestrial lizard. Sci. Rep. 6:22207. doi: 10.1038/srep22207

Piper, W. H., Parker, P. G., and Rabenold, K. N. (1995). Facultative dispersal by juvenile males in the cooperative stripe-backed wren. Behav. Ecol. 6, 337-342. doi: 10.1093/beheco/6.3.337

Popp, J. N., Hamr, J., Larkin, J. L., and Mallory, F. F. (2018). Black bear (Ursus americanus) and wolf (Canis spp.) summer diet composition and ungulate prey selectivity in Ontario, Canada. Mammal Res. 63, 433-441. doi: 10.1007/s13364-018-0368-y

Post, M. J. (2000). The captive husbandry and reproduction of the Hosmer's Skink Egernia hosmeri. Herpetof. Syd. 30, 2-6.

Prager, S. M. (2014). Comparison of social and solitary nesting carpenter bees in sympatry reveals no advantage to social nesting. Biol. J. Linn. Soc. 113, 998-1010. doi: 10.1111/bij.12395

Purcell, J., and Avilés, L. (2008). Gradients of precipitation and ant abundance may contribute to the altitudinal range limit of subsocial spiders: insights from a transplant experiment. Proc. R. Soc. B Biol. Sci. 275, 2617-2625. doi: $10.1098 /$ rspb.2008.0582

Queller, D. C., Zacchi, F., Cervo, R., Turillazzi, S., Henshaw, M. T., Santorelli, L. A., et al. (2000). Unrelated helpers in a social insect. Nature 405, 784-787. doi: 10.1038/35015552

Rabosky, A. R., Corl, A., Liwanag, H. E., Surget-Groba, Y., and Sinervo, B. (2012). Direct fitness correlates and thermal consequences of facultative aggregation in a desert lizard. PLoS ONE 7:e40866. doi: 10.1371/journal.pone.0040866

Radespiel, U., Sarikaya, Z., Zimmermann, E., and Bruford, M. W. (2001). Sociogenetic structure in a free-living nocturnal primate population: sexspecific differences in the grey mouse lemur (Microcebus murinus). Behav. Ecol. Sociobiol. 50, 493-502. doi: 10.1007/s002650100402

Reyer, H.-U. (1986). Breeder-helper-interactions in the pied kingfisher reflect the costs and benefits of cooperative breeding. Behaviour 96, 277-302. doi: 10.1163/156853986X00522

Riehl, C. (2013). Evolutionary routes to non-kin cooperative breeding in birds. Proc. R. Soc. Lond. B Biol. Sci. 280:20132245. doi: 10.1098/rspb.2013.2245

Ross, C. (2001). Park or ride? Evolution of infant carrying in primates. Int. J. Primatol. 22, 749-771. doi: 10.1023/A:1012065332758

Royle, N. J., Alonzo, S. H., and Moore, A. J. (2016). Co-evolution, conflict and complexity: what have we learned about the evolution of parental care behaviours? Curr. Opin. Behav. Sci. 12, 30-36. doi: 10.1016/j.cobeha.2016.08.004

Royle, N. J., Smiseth, P. T., and Kölliker, M. (Eds.). (2012). The Evolution of Parental Care. Oxford; New York, NY: Oxford University Press.
Rubenstein, D. R., and Abbot, P. (2017a). Comparative Social Evolution. Cambridge, UK: Cambridge University Press.

Rubenstein, D. R., and Abbot, P. (2017b). "Social synthesis: opportunities for comparative social evolution," in Comparative Social Evolution, eds D. R. Rubenstein and P. Abbot (Cambridge, UK: Cambridge University Press), 427-452.

Rubenstein, D. R., Botero, C. A., and Lacey, E. A. (2016). Discrete but variable structure of animal societies leads to the false perception of a social continuum. R. Soc. Open Sci. 3:160147. doi: 10.1098/rsos.160147

Schülke, O., and Kappeler, P. M. (2003). So near and yet so far: territorial pairs but low cohesion between pair partners in a nocturnal lemur, Phaner furcifer. Anim. Behav. 65, 331-343. doi: 10.1006/anbe.2003.2018

Schwarz, M. P., Bull, N. J., and Cooper, S. J. (2003). Molecular phylogenetics of allodapine bees, with implications for the evolution of sociality and progressive rearing. Syst. Biol. 52, 1-14. doi: 10.1080/10635150390132632

Sheehan, M. J., Botero, C. A., Hendry, T. A., Sedio, B. E., Jandt, J. M., Weiner, S., et al. (2015). Different axes of environmental variation explain the presence vs. extent of cooperative nest founding associations in Polistes paper wasps. Ecol. Lett. 18, 1057-1067. doi: 10.1111/ele.12488

Shultz, S., Opie, C., and Atkinson, Q. D. (2011). Stepwise evolution of stable sociality in primates. Nature 479:219. doi: 10.1038/nature 10601

Silk, J. B., and Kappeler, P. M. (2017). "Sociality in primates," in Comparative Social Evolution, eds D. R. Rubenstein and P. Abbot (Cambridge, UK: Cambridge University Press), 253-283.

Sloane, S. A. (1996). Incidence and origins of supernumeraries at bushtit (Psaltriparus minimus) nests. Auk 113, 757-770. doi: 10.2307/4088855

Soucy, S. L., and Giray, T. (2003). Solitary and group nesting in the orchid bee Euglossa hyacinthina (Hymenoptera, Apidae). Insectes Sociaux 50, 248-255. doi: 10.1007/s00040-003-0670-8

Stacey, P. B., and Ligon, J. D. (1991). The benefits-of-philopatry hypothesis for the evolution of cooperative breeding: variation in territory quality and group size effects. Am. Nat. 137, 831-846. doi: 10.1086/285196

Stern, D. L. (1998). Phylogeny of the tribe Cerataphidini (Homoptera) and the evolution of the horned soldier aphids. Evolution 52, 155-165. doi: 10.1111/j.1558-5646.1998.tb05148.x

Stevens, M. I., Hogendoorn, K., and Schwarz, M. P. (2007). Evolution of sociality by natural selection on variances in reproductive fitness: evidence from a social bee. BMC Evol. Biol. 7:153. doi: 10.1186/1471-2148-7-153

Strassmann, J. E., Hughes, C. R., Turillazzi, S., Solis, C. R., and Queller, D. C. (1994). Genetic relatedness and incipient eusociality in stenogastrine wasps. Anim. Behav. 48, 813-821. doi: 10.1006/anbe.1994.1305

Tallamy, D. W., and Wood, T. K. (1986). Convergence patterns in subsocial insects. Annu. Rev. Entomol. 31, 369-390. doi: 10.1146/annurev.en.31.010186.002101

Thierry, B. (2008). Primate socioecology, the lost dream of ecological determinism. Evol. Anthropol. Issues News Rev. Issues News Rev. 17, 93-96. doi: 10.1002/evan.20168

Thorne, B. L. (1997). Evolution of eusociality in termites. Annu. Rev. Ecol. Syst. 28, 27-54. doi: 10.1146/annurev.ecolsys.28.1.27

Tullberg, B. S., Ah-King, M., and Temrin, H. (2002). Phylogenetic reconstruction of parental-care systems in the ancestors of birds. Philos. Trans. R. Soc. Lond. B. Biol. Sci. 357, 251-257. doi: 10.1098/rstb.2001.0932

Turnbull, C., Caravan, H., Chapman, T., Nipperess, D., Dennison, S., Schwarz, M., et al. (2012). Antifungal activity in thrips soldiers suggests a dual role for this caste. Biol. Lett. 8, 526-529. doi: 10.1098/rsbl.2012.0184

van Schaik, C. (1983). Why are diurnal primates living in groups? Behaviour 87, 120-144. doi: 10.1163/156853983X00147

van Schaik, C. P., and Kappeler, P. M. (1997). Infanticide risk and the evolution of male-female association in primates. Proc. R. Soc. Lond. B Biol. Sci. 264, 1687-1694. doi: 10.1098/rspb.1997.0234

Varricchio, D. J., Moore, J. R., Erickson, G. M., Norell, M. A., Jackson, F. D., and Borkowski, J. J. (2008). Avian paternal care had dinosaur origin. Science 322, 1826-1828. doi: 10.1126/science. 1163245

Viera, C., and Agnarsson, I. (2017). "Parental care and sociality," in Behaviour and Ecology of Spiders, eds C. Viera and M. Gonzaga (Cham: Springer), 351-381.

Walters, J. R., Copeyon, C. K., and Carter Iii, J. H. (1992). Test of the ecological basis of cooperative breeding in red-cockaded woodpeckers. Auk 109, 90-97. doi: $10.2307 / 4088269$ 
Wcislo, W., and Fewell, J. H. (2017). "Sociality in bees," in Comparative Social Evolution, eds D. R. Rubenstein and P. Abbot (Cambridge, UK: Cambridge University Press), 50-83.

Wcislo, W. T., and Tierney, S. M. (2009). "The evolution of communal behavior in bees and wasps: an alternative to eusociality", in Organization of Insect Societies: From Genome to Sociocomplexity, eds J. Gadau and J. H. Fewell (Cambridge, MA: Harvard University Press), 148-169.

Wcislo, W. T., Wille, A., and Orozco, E. (1993). Nesting biology of tropical solitary and social sweat bees, Lasioglossum (Dialictus) figueresi Wcislo and L. (D.) aeneiventre (Friese) (Hymenoptera: Halictidae). Insectes Sociaux 40, 21-40. doi: 10.1007/BF01338830

Wenzel, J. W., and Pickering, J. (1991). Cooperative foraging, productivity, and the central limit theorem. Proc. Natl. Acad. Sci. U.S.A. 88, 36-38. doi: $10.1073 /$ pnas.88.1.36

Wesolowski, T. (1994). On the origin of parental care and the early evolution of male and female parental roles in birds. Am. Nat. 143, 39-58. doi: $10.1086 / 285595$

West-Eberhard, M. J. (1975). The evolution of social behavior by kin selection. Q. Rev. Biol. 50, 1-33. doi: 10.1086/408298

Wheeler, W. M. (1928). The Social Insects: Their Origin and Evolution. Abingdon: Routledge.

Wolff, J. O. (1994). Reproductive success of solitarily and communally nesting white-footed mice and deer mice. Behav. Ecol. 5, 206-209. doi: 10.1093/beheco/5.2.206

Wong, M. Y. (2010). Ecological constraints and benefits of philopatry promote group-living in a social but non-cooperatively breeding fish. Proc. R. Soc. B Biol. Sci. 277, 353-358. doi: 10.1098/rspb.2009.1453
Wong, M. Y., Buston, P. M., Munday, P. L., and Jones, G. P. (2007). The threat of punishment enforces peaceful cooperation and stabilizes queues in a coral-reef fish. Proc. R. Soc. B Biol. Sci. 274, 1093-1099. doi: 10.1098/rspb.20 06.0284

Wong, M. Y. L., Fauvelot, C., Planes, S., and Buston, P. M. (2012). Discrete and continuous reproductive tactics in a hermaphroditic society. Anim. Behav. 84, 897-906. doi: 10.1016/j.anbehav.2012.07.013

Wrangham, R. W. (1980). An ecological model of female-bonded primate groups. Behaviour 75, 262-300. doi: 10.1163/156853980X00447

Yamamoto, M. E. (2006). Infant care in callitrichids: cooperation and competition. Annu. Rev. Biomed. Sci. 7, 149-160.

Yip, E. C., and Rayor, L. S. (2014). Maternal care and subsocial behaviour in spiders. Biol. Rev. 89, 427-449. doi: 10.1111/brv.12060

Zink, A. G. (2000). The evolution of intraspecific brood parasitism in birds and insects. Am. Nat. 155, 395-405. doi: 10.1086/303325

Conflict of Interest Statement: The authors declare that the research was conducted in the absence of any commercial or financial relationships that could be construed as a potential conflict of interest.

Copyright (๑) 2019 Socias-Martinez and Kappeler. This is an open-access article distributed under the terms of the Creative Commons Attribution License (CC BY). The use, distribution or reproduction in other forums is permitted, provided the original author(s) and the copyright owner(s) are credited and that the original publication in this journal is cited, in accordance with accepted academic practice. No use, distribution or reproduction is permitted which does not comply with these terms. 